UNIVERSIDADE DE SÃO PAULO

FACULDADE DE ECONOMIA, ADMINISTRAÇÃO E CONTABILIDADE DEPARTAMENTO DE ECONOMIA

PROGRAMA DE PÓS-GRADUAÇÃO EM ECONOMIA

\title{
Lei de Cotas e a escolha de escola no ensino
}

\author{
básico
}

Thiago Guimarães Cardoso

Orientador: Prof. Dr. Ricardo de Abreu Madeira

São Paulo - Brasil

2016 
Prof. Dr. Marco Antonio Zago

Reitor da Universidade de São Paulo

Prof. Dr. Adalberto Américo Fischmann

Diretor da Faculdade de Economia, Administração e Contabilidade

Prof. Dr. Hélio Nogueira da Cruz

Chefe do Departamento de Economia

Prof. Dr. Márcio Issao Nakane

Coordenador do Programa de Pós-Graduação em Economia 


\title{
THIAGO GUIMARÃES CARDOSO
}

\section{Lei de Cotas e a escolha de escola no ensino}

\section{básico}

Dissertação apresentada ao Departamento de Economia da Faculdade de Economia, Administração e Contabilidade da Universidade de São Paulo como requisito parcial para a obtenção do título de Mestre em Ciências.

Orientador: Prof. Dr. Ricardo de Abreu Madeira

\begin{abstract}
Versão Corrigida
(versão original disponível na Biblioteca da Faculdade de Economia, Administração e Contabilidade)
\end{abstract}

São Paulo - Brasil

2016 
FICHA CATALOGRÁFICA

Elaborada pela Seção de Processamento Técnico do SBD/FEA/USP

Cardoso, Thiago Guimarães

Lei de cotas e a escolha de escola no ensino básico / Thiago

Guimarães Cardoso. - São Paulo, 2016.

$70 \mathrm{p}$.

Dissertação (Mestrado) - Universidade de São Paulo, 2016.

Orientador: Ricardo de Abreu Madeira.

1. Ação afirmativa 2. Lei de cotas 3. School choice I. Universidade de São Paulo. Faculdade de Economia, Administração e Contabilidade. II. Título.

$$
\text { CDD - } 320.6
$$




\section{Lei de Cotas e a escolha de escola no ensino básico}

Dissertação apresentada ao Departamento de Economia da Faculdade de Economia, Administração e Contabilidade da Universidade de São Paulo como requisito parcial para a obtenção do título de Mestre em Ciências.

Prof. Dr. Ricardo de Abreu Madeira

Orientador

Profa. Dra.

Fernanda Gonçalves de La Fuente Estevan

Prof. Dr.

André Portela Fernandes de Souza

Prof. Dr.

Luiz Guilherme Dácar da Silva Scorzafave

São Paulo - Brasil

2016 

Dedico este trabalho à Luisa, minha grandínea companheira 



\section{Agradecimentos}

Agradeço a Deus, pela imensa paciência que vem demonstrando por mim.

Agradeço ao meu pai, Valtair, pela inesgotável fonte de caráter e sabedoria, que me servem todos os dias de exemplo para traçar melhores caminhos.

Agradeço à minha mãe, Mara, pela paciência, generosidade e carinho ao longo de todos estes anos. Agradeço também por ser meu grande exemplo de força.

Agradeço ao Centro de Estudios Distributivos, Laborales y Sociales (CEDLAS) da Universidade Nacional de La Plata e à Coordenação de Aperfeiçoamento do Ensino Superior (CAPES) pelo apoio financeiro concedido para realização deste trabalho. 



\section{Resumo}

O objetivo desse trabalho é identificar se a Lei de $\operatorname{Cotas}^{1}$ tem impacto sobre a probabilidade de migração para a rede pública dos alunos matriculados em escola privadas no ensino básico. Como antes de 2012 a maior parte das universidades federais brasileiras já adotavam alguma ação afirmativa, analisamos com maior profundidade, a partir da metodologia de Diferenças-em-Diferenças, o impacto da Lei em dois estados: Minas Gerais e São Paulo. Em Minas Gerais, estado onde a Lei representa uma mudança institucional significativa no acesso ao ensino superior público, estimamos um aumento de $20 \%$ na probabilidade média de migração da coorte tratada. Já em São Paulo, onde essa mudança não ocorre no mesmo nível, o aumento estimado é inferior a $8 \%$. Estimamos ainda que, tanto em Minas Gerais, quanto em São Paulo, a Lei de Cotas tem menor impacto sobre os alunos provenientes de escolas privadas de maior qualidade.

Palavras-chaves: Ação afirmativa; Lei de Cotas; School choice.

$1 \quad$ Lei sancionada pelo governo brasileiro em 2012 que reserva 50\% das vagas em todas as universidades federais para alunos que estudaram o ensino médio integralmente em escolas da rede pública. 



\section{Abstract}

This thesis intends to identify if the Law of Social Quotas ${ }^{2}$ has an impact on the school choice of students enrolled in private elementary schools. As before 2012 most Brazilian federal universities already had adopted some affirmative action, we analyze, building on a Diff-Diff methodology, the impact of the Law in two states: Minas Gerais and São Paulo. In Minas Gerais, state where the law represents a significant institutional change in the access to public higher education, we estimate a $20 \%$ increase in the average probability of migration of the treated cohort. In São Paulo, where this change does not occur at the same level, the estimated increase is below $8 \%$. We also estimate that both in Minas Gerais and São Paulo the Law have lower impact on students from higher quality private schools.

Key-words: Affirmative action; Law of Social Quotas; School choice

$2 \quad$ Law enacted by the Brazilian government in 2012 that guarantees $50 \%$ of the seats in all federal universities for students who studied all high school period in public schools. 



\section{Lista de tabelas}

Tabela 1 - Nota no IDEB por rede de ensino - Minas Gerais e São Paulo . . . . . 24

Tabela 2 - Ações afirmativas implementadas antes da Lei de Cotas . . . . . . . . . 32

Tabela 3 - Testes de média das características socioeconômicas . . . . . . . . . . . 41

Tabela 4 - Número de alunos por coorte de controle e tratamento . . . . . . . . 43

Tabela 5 - Reprovação e abandono escolar por coorte de controle e tratamentoMinas Gerais e São Paulo . . . . . . . . . . . . . . . . . . . . . 45

Tabela 6 - Impacto da Lei de Cotas sobre a escolha de escola . . . . . . . . . . . . 49

Tabela 7 - Impacto da Lei de Cotas sobre a escolha de escola - Alunos que estudaram os últimos 3 anos em escolas privadas . . . . . . . . . . . . 50

Tabela 8 - Percentual de escolas por item de infraestrutura e percentual médio de professores com pós graduação . . . . . . . . . . . . . . 51

Tabela 9 - Impacto da Lei de Cotas sobre a escolha de escola - Análise de hetero-

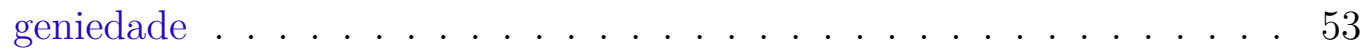

Tabela 10 - Impacto da Lei de Cotas sobre a escolha de escola - Segundo grupo de

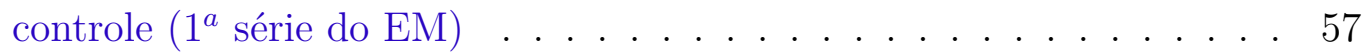





\section{Sumário}

1 Introdução . . . . . . . . . . . . . . . . . . 19

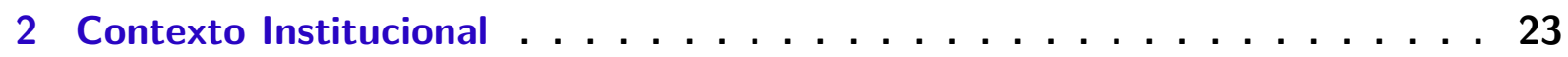

2.1 Lei de Cotas e Ações Afirmativas no Brasil . . . . . . . . . . . . . . . 27

3 Revisão de Literatura . . . . . . . . . . . . . . . . . . . . 33

3.1 Ações Afirmativas e a Escolha de Escola . . . . . . . . . . . . . . . . . . 33

3.2 Determinantes da Escolha de Escola . . . . . . . . . . . . . . . . 35

4 Método de Identificação . . . . . . . . . . . . . . . . . . 37

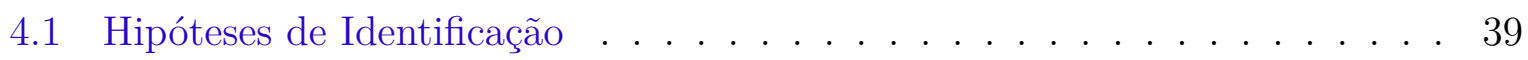

5 Dados . . . . . . . . . . . . . . . . . . 43



6 Resultados . . . . . . . . . . . . . . . . . . 47

7 Heterogeniedade . . . . . . . . . . . . . . 51

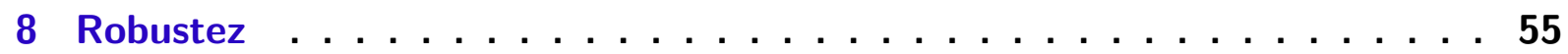

9 Conclusão . . . . . . . . . . . . . . . . . . 59

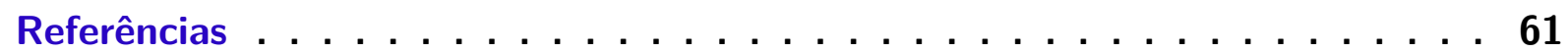

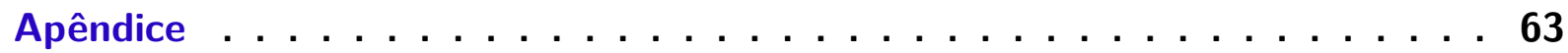





\section{Introdução}

Em Agosto de 2012, foi sancionada a lei $n^{o}$ 12.711, mais conhecida como Lei de Cotas (LC). De acordo com a Lei, todas as universidades federais brasileiras devem reservar $50 \%$ de suas vagas para alunos que estudaram o ensino médio (EM) integralmente em escolas da rede pública. Como no Brasil um dos principais objetivos dos alunos que se matriculam em uma escola privada no EM é o de ingressar em uma instituição pública de ensino superior, esperamos que a LC gere um incentivo para que alunos no último ano do ensino fundamental (EF) migrem para escola pública na primeira série do EM. Partindo dessa mudança institucional, o objetivo deste trabalho é identificar e quantificar o possível impacto da LC sobre a escolha de escola de alunos matriculados em escolas privadas de ensino básico no país.

Para isso, utilizaremos a metodologia de Diferenças-em-Diferenças. O grupo de tratamento será composto pelos alunos matriculados no $9^{\circ}$ ano do EF em escolas da rede privada em 2009, 2010, 2011, 2012, 2013 e 2014³. A LC entra em vigor em 2012 e já vale para o primeiro vestibular de $2013^{4}$, dessa forma, todos os alunos do grupo de tratamento matriculados em escola privada no ano de 2012 são afetados pela Lei. Já o grupo de controle será composto pelos alunos matriculados no $5^{\circ}$ ano do $\mathrm{EF}$ em escolas privadas no mesmo período. Diferentemente dos alunos matriculados no $9^{\circ}$ ano em 2012, os alunos de $5^{\circ}$ ano não são afetados, já que a LC beneficia aqueles que estudaram apenas o EM na rede pública e, portanto, a decisão de migrar ou não para rede pública no $6^{\circ}$ ano do $\mathrm{EF}$ não irá definir se serão beneficiados ${ }^{5}$.

Como as mudanças impostas pela Lei valem apenas para as universidades federais, esperamos que seu impacto seja maior nos estados onde a parcela de vagas nas universidades

3 A base que permite a identificação da migração entre redes de ensino a nível populacional é disponibilizada desde 2007 pelo Instituo Nacional de Estudos e Pesquisas Educacionais Anísio Teixeira (INEP). Contudo, nos dois primeiros anos de divulgação da base, há falhas na reportação dos alunos matriculados no ensino básico por parte das escolas, o que gera grande percentual de atrito quando analisadas as coortes 2007 e 2008. Optamos então por iniciar nossa análise a partir de 2009.

4 A sanção da Lei e consequentemente sua informação à sociedade ocorre no mês de Setembro, enquanto a escolha de escola é, em geral, feita ao fim do ano ou no início do próximo ano letivo.

5 Na seção posterior iremos discutir a hipótese de antecipação da mudança para rede pública por parte dos alunos do grupo de controle. 
federais dentro do sistema de ensino superior seja maior. Ainda, há estados onde as universidades federais já implementavam ações afirmativas (AA) semelhantes à LC antes de 2012. Portanto, nesses locais a Lei não representa uma mudança institucional significativa no acesso ao ensino superior. Para contornar essas questões, realizamos uma delimitação da base, com o intutio de analisar com maior profundidade dois estados: Minas Gerais e São Paulo.

Observamos que em Minas Gerais, estado onde mais de $80 \%$ das vagas em universidades públicas estão em universidades federais e que apenas 1 das 11 universidades federais do estado adotava uma AA semelhante à LC antes de 2012, a Lei é responsável por um aumento de 2,2 p.p na probabilidade de migração, quando analisadas as coortes 2011 e 2012, o que representa um variação de $20 \%$ na probabilidade média de migração do grupo de tratamento de um ano para outro. Já em São Paulo, onde apenas 15\% dos alunos matriculados em instituições de ensino superior (IES) públicas estão em universidades federais e 2 das 3 universidades federais presentes no estado adotavam AA semelhantes à LC antes de 2012, o impacto da Lei é de 1,2 p.p., um aumento inferior a 8\%. Quando analisamos um período mais longo, utilizando 3 coortes pré e 3 coortes pós Lei de Cotas, o impacto para Minas Gerais é ainda maior, 4,5 p.p., e o impacto encontrado para São Paulo é estatisticamente igual a zero.
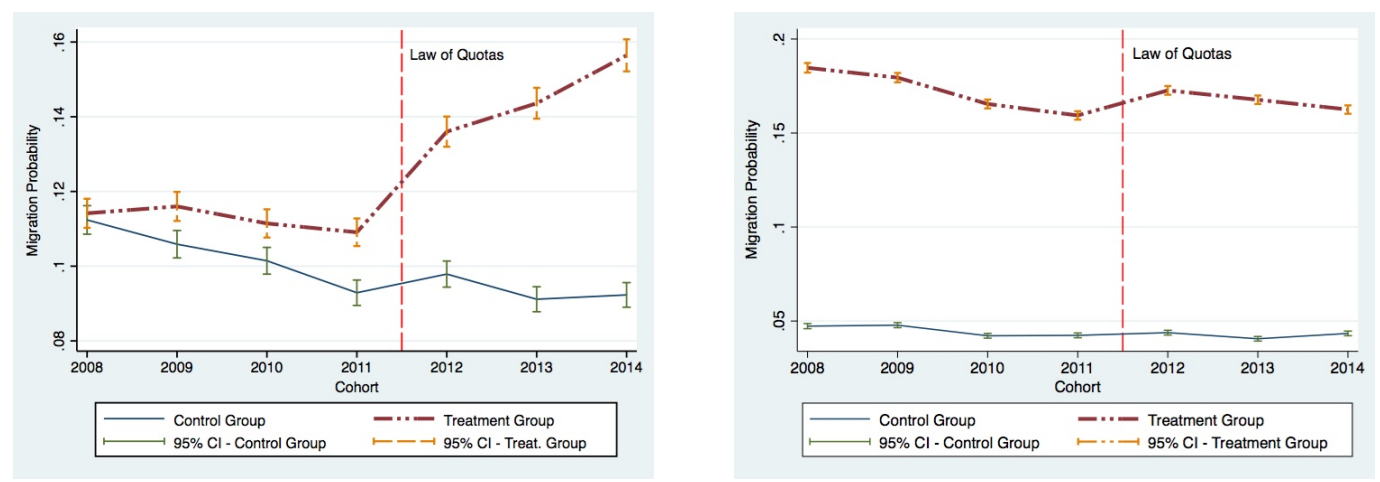

Figura 1 - Evolução da probabilidade de migração para rede pública - Minas Gerais e São Paulo

Observamos ainda que, tanto em Minas Gerais, quanto em São Paulo, o impacto da lei é menor para alunos provenientes de escolas privadas com maior percentual de professores 
com pós-graduação. Considerando que a proporção de professores com pós graduação em uma escola é indicativo de sua qualidade, observamos que nas "melhores"escolas o impacto da Lei tende a ser menor.

Por fim, realizamos exercícios de robustez para verificar o impacto da Lei a partir de um diferente grupo de controle, os alunos matriculados na $1^{a}$ série do EM em escola privada, e estimamos os coeficientes de interesse para períodos placebo, em que a Lei ainda não estava em vigor. Em relação à primeira análise, verificamos que, mesmo utilizando outro grupo de controle, o impacto da Lei, apesar de inferior, ainda é positivo e estasticamente significante à $1 \%^{6}$. Já nas regressões para os períodos placebo, não observamos impacto da Lei em nenhum dos períodos anteriores à sua implementação no estado de Minas Gerais. Em São Paulo, encontramos um pequeno impacto negativo, portanto inverso ao impacto esperado da Lei, que perde a significância quando consideramos nível de significância à $1 \%$.

Os resultados encontrados nesta dissertação corroboram as evidências apresentadas em trabalhos recentes que analisam o impacto de AA do tipo color-blind na escolha de escola, como Estevan et al. (2012) e Cullen, Long e Reback (2013). Concluímos que a implementação de AA que beneficiam um grupo específico de escolas no acesso ao ensino superior, pode levar a um comportamento estratégico na escolha de escola dos alunos matriculados no ensino básico. No caso da Lei de Cotas, há um incentivo para migração para rede pública de ensino no $1^{\circ}$ do EM, especialmente para os alunos provientens de escolas privadas de pior qualidade.

Este trabalho prosseguirá da seguinte forma: Primeiramente, será exposto um panorama da educação básica no Brasil, seguido pela revisão de literatura. No quarto e quinto capítulos, serão apresentadas a estratégia de identificação e a base de dados utilizada. Por fim, no capítulos seguintes, são apresentados os resultados encontrados e os exercicios de heterogeniedade e robustez, seguidos pela conclusão deste trabalho.

6 Com exceção da especificação em que incluímos cluster para escola e ano e são utilizadas apenas duas coortes. 



\section{Contexto Institucional}

No Brasil, o ensino superior é composto por instituições privadas de ensino, com ou sem fins lucrativos, e instituições públicas, que podem ser vinculadas à esfera Federal, Estadual ou Municipal. Cerca de $71 \%$ dos alunos matriculados em cursos presenciais de ensino superior estudam em instituições privadas. Em relação aos alunos matriculados no sistema público, cerca de $63 \%$ estão matriculados em instituições federais, $33 \%$ em estaduais e menos de $5 \%$ em municipais ${ }^{7}$. As instituições públicas são obrigatoriamente gratuitas enquanto as privadas são, em sua grande maioria, pagas.

Esses percentuais se alteram de acordo com o estado de análise. Em Minas Gerais, estado com o segundo maior número de alunos matriculados em universidades públicas, as universidades federais tem um papel preponderante. Cerca de $87 \%$ dos alunos matriculados no sistema público de ensino superior estudam em uma das 11 universidades federais presentes no estado, maior número em uma única unidade federativa. Por outro lado, em São Paulo, esse montante é de apenas $15 \%$ e há apenas 3 universidades federais para o estado com o maior número de alunos no sistema público de ensino superior.

Além da gratuidade, as universidades públicas são reconhecidamente as IES de maior renome e qualidade no país. A título de ilustração, das 9 universidades com nota máxima no Índice Geral de Cursos, ranking elaborado pelo MEC, 8 são instituições públicas. A consequência desses fatores, gratuidade e qualidade, é a alta competição por uma vaga nessas instituições. Nas universidades públicas há uma média de 21,3 candidatos inscritos por vaga oferecida, comparado à média de 2,3 nas instituições privadas.

Nessa disputa, levam vantagem os alunos que tiveram um melhor preparo durante o ensino básico, que, contrariamente ao que ocorre no ensino superior, são aqueles que estudaram em escolas da rede privada. Na Universidade de São Paulo (USP), IES brasileira melhor ranqueada em avalições internacionais, 28,5\% dos alunos ingressantes em 2013 cursaram o EM em escolas públicas, enquanto no município de São Paulo cerca de $82 \%$

\footnotetext{
$7 \quad$ Sinopse Estatística da Educação Superior, 2013. INEP
} 
dos alunos de EM estão matriculados na rede pública de ensino ${ }^{8}$.

Em 2013, a nota do IDEB $^{9}$ para as escolas privadas de ensino médio em Minas Gerais era de 5,8, comparado à nota de 3,6 das escolas públicas. Em São Paulo observamos uma diferença inferior, porém substancial. A nota das escolas privadas é de 5,6 , enquanto das escolas públicas é de 4,5. Essas diferenças se agravam quando comparamos escolas de EF, como pode ser observado na tabela (1).

Levando em consideração o ENEM, principal porta de acesso às universidades federais do país, observamos que a diferença de rendimento se mantém. Em 2012, a nota média na prova de matemática das escolas particulares em Minas Gerais foi de 617 pontos, enquanto na pública a nota alcançada foi de 488 pontos. Novamente, os resultados são semelhantes para o estado de São Paulo. Enquanto a nota das escolas privadas foi de 604 pontos, a das pública foi de 483 pontos.

Tabela 1 - Nota no IDEB por rede de ensino - Minas Gerais e São Paulo

\begin{tabular}{lcccccc} 
& \multicolumn{2}{c}{ Minas Gerais } & & \multicolumn{2}{c}{ São Paulo } \\
\cline { 2 - 3 } \cline { 5 - 6 } & Pública & Privada & & Pública & Privada \\
\hline \hline EM & 3,6 & 5,8 & & 4,5 & 5,6 \\
EF- anos finais & 4,6 & 6,3 & & 4,4 & 6,3 \\
EF - anos inicias & 5,9 & 7,6 & & 5,8 & 7,3 \\
\hline \hline
\end{tabular}

Fonte: INEP.

Não apenas o rendimento dos alunos das escolas privadas em avaliações externas e vestibulares é superior, como a taxa de participação nas provas. Em Minas Gerais, 25.588 alunos de escolas privadas e 110.356 alunos de escolas públicas realizaram o ENEM em 2012. Esses valores representam $97 \%$ e $55 \%$ do total de alunos matriculados no último ano do EM em cada uma das redes, respectivamente. Já em São Paulo, a adesão ao ENEM é

8 Emilio, Jr e Alves (2004) identificam um aumento significante na probabilidade de ingresso na USP para os alunos que cursaram o EM apenas em escolas particulares e/ou realizaram um curso preparatório para o vestibular.

9 O índice nacional da educação básica (IDEB) é calculado pelo MEC com o objetivo de avaliar o sistema de ensino básico no Brasil. A nota é calculada com base em um indicador de aprendizado, medido por meio de avaliação educacional externa, e um indicador de fluxo, medido a partir das taxas de aprovação, evasão e distorção idade-série. 
muito inferior ao observado em Minas Gerais. O número de alunos que realizaram o ENEM no estado em 2012 representa cerca de $79 \%$ dos alunos das escolas privadas e apenas $45 \%$ dos alunos das escolas públicas.

Essa diferença na adesão ao ENEM ocorre por um motivo. A forma de ingresso nas universidades brasileiras é, em geral, realizada por meio de provas anuais ou semestrais, denominadas vestibulares, e os estudantes são selecionados de acordo com sua classificação neste exame ${ }^{10}$. Todas universidades federais adotam o ENEM como toda ou uma parte significante do vestibular. Já as universidades estaduais de São Paulo, USP e Unicamp, possuem um sistema de ingresso próprio que apenas recentemente passou a incluir a nota do ENEM como uma parcela minoritária da nota final de seus vestibulares ${ }^{11}$.

Contudo, o que não muda de um estado para outro é a relevância dos universidades públicas no sistema de ensino superior. No Brasil, um dos principais objetivos das famílias que matriculam seus filhos em escolas privadas durante o ensino básico é o de aumentar a chance de ingresso em uma universidade pública ${ }^{12}$. Isso não se reflete apenas na diferença no desempenho das escolas privadas em avaliações externas e provas de ingressos nas universidades, mas pelo próprios sistemas de ensino e propostas pedagógicas adotados

$10 \quad$ Nas universidades públicas, 92\% dos estudantes foram selecionados por meio do vestibular, enquanto nas privadas, cerca de 86\%. Sinopse Estatística da Educação Superior, 2013. INEP

11 Em 2015, a USP aprovou a reserva de cerca de 13,5\% das vagas dos cursos de graduação para o ENEM. Já na UNICAMP, a nota no ENEM pode responder por $20 \%$ da nota final de um candidato na $1^{a}$ fase do vestibular da instituição.

12 Vale ressaltar que, no período anterior à implementação da Lei de Cotas, duas políticas de larga escala foram implementadas pelo governo federal com o intuito de intensificar o acesso ao ensino superior, o Prouni e o FIES. O Prouni é um programa que destina bolsas parcial ou integrais em instituições privadas de ensino superior para alunos que estudaram o ensino médio integralmente na rede pública ou com bolsas integrais em escolas privadas. Esse programa foi instituído em 2004 e, em 2014, atingiu um total de 306 mil bolsas ofertadas. Dois fatores devem ser ressaltados: i) De 2009 a 2013 não houve alteração significativa no número de bolsas concedidas pelo programa, portanto não houve uma mudança significativa do Prouni em 2012, ano de implementação da Lei de Cotas; ii) A data de inscrição para pleitear uma bolsa no programa é posterior à realização e divulgação do resultados dos vestibulares, portanto os alunos que buscam uma vaga em IES pública não têm certeza de que terão uma bolsa em uma universidade privada no ano seguinte. Já o FIES é um programa que concede financiamento à taxas de juros subsidiadas(Cerca de $3 \%$ a.a.) para alunos com renda familiar per capita inferior à 2,5 salários mínimos. O FIES foi instituído pela Lei 10.260 de 2001 e, em 2014, financiava cerca de 30\% dos estudantes matriculados em IES do país(Associação Nacional dos Dirigentes das Instituições Federais de Ensino Superior (ANDIFES).). Como o grupo beneficiário do FIES é diferente do especificado pela Lei de Cotas, levando em consideração apenas a renda dos alunos, não consideramos que essa política tenha impacto sobre a escolha de escolas dos alunos no ensino básico. 
pelas escolas privadas, especialmente no EM, que são, em grande medida, voltados para o resultado nos vestibulares. A nota média dos alunos de uma escola no ENEM é o principal indicador de qualidade utilizado pelas instituições de ensino básico e o número de aprovados nas principais universidades públicas do país é constantemente utilizado como marketing pelas escolas. Dessa forma, o investimento em uma escola privada de maior qualidade durante o ensino básico é um meio para aumentar as chances ingresso em uma IES pública, que além de gratuitas são, em geral, as instituições mais renomadas no país. 


\subsection{Lei de Cotas e Ações Afirmativas no Brasil}

Sancionada em 29 de Agosto de 2012 a lei $n^{\circ}$ 12.711, mais conhecida como Lei de Cotas, decreta que no mínimo 50\% das vagas oferecidas em instituições federais de ensino superior deverão ser reservadas para estudantes que tenham cursado o EM integralmente na rede pública de ensino, sendo que metade dessas vagas deverá ser preenchida por alunos oriundos de famílias com renda inferior a 1,5 salários mínimos. Ainda, as vagas reservadas deverão ser preenchidas em proporção no mínimo igual à de pretos, pardos e indígenas na população da unidade da Federação onde está instalada a instituição, segundo o último Censo do Instituto Brasileiro de Geografia e Estatística (IBGE) ${ }^{13}$. As universidades federais tiveram um prazo de 4 anos para cumprir integralmente a reserva de cotas exigida pela Lei, sendo que, já em 2013, ao menos 25\% das vagas deveriam ser reservadas para estudantes dos grupos beneficiários. A figura 1 apresenta um exemplo de como as vagas devem ser preenchidas em um curso com 100 vagas.



Figura 2 - Número mínimo de vagas garantidas pela Lei

Antes de analisar o impacto da Lei de Cotas, cabe averiguar se esta medida representa uma mudança significantiva no acesso ao sistema de ensino superior público no Brasil. Antes da implementação da Lei, a maior parte das universidades públicas brasileiras já adotavam alguma forma de ação afirmativa. Dessa forma, apesar de seu 
caráter impositivo, a LC serviu mais para balizar e instituir um percentual mínimo de vagas reservadas do que inaugurar a adoção de AA no país.

Em 2012, ano em que a Lei ainda não estava em vigor, 30.264 vagas já haviam sido reservadas para algum tipo de política em universidades federais. Contudo, não havia homogeneidade na definição dos beneficiários. Enquanto em algumas instituições eram contemplados apenas estudantes negros e pardos, em outras as cotas só valiam para estudantes que haviam cursado metade do EF e todo o EM na rede pública e/ou provenientes de famílias de baixa renda. Ao contemplar tanto estudantes de escolas públicas, como negros e pardos e de baixa renda, além de criar um patamar mínimo para a adoção de cotas, a LC dá um caráter unificado à este tipo de política no país.

Não é do escopo deste trabalho discutir se tal centralização na definição de AA é positiva ou não, contudo vale ressaltar a significativa expansão no número de vagas reservadas. No primeiro ano da Lei, 2013, 59.432 foram reservadas para cotas, um aumento de quase $50 \%$ em relação ao ano anterior. O ritmo de expansão se manteve no ano posterior, atingindo um total de 77.374 vagas em 2014 Junior et al. (2013).

Para compreender com maior profundidade a mundança que a Lei representa, iremos delimitar nossa base para analisar dois estados brasileiros, Minas Gerais e São Paulo. A escolha dessas duas regiões se dá por três motivos principais:

1 São os dois estados com o maior número de alunos matriculados no ensino superior no país;

2 Em ambos estados, o percentual de alunos matriculados no ensino superior em IES públicas que nasceram no estado é de aproximadamente $90 \%$, o que indica um alto grau de regionalização das universidades públicas;

3 Enquanto Minas Gerais tem a maior proporção de alunos do sistema público de ensino superior matriculados em universidades federais dentre os cinco maiores estados, $87 \%$, São Paulo tem a menor, 15\%. Como a Lei de Cotas vale apenas para as universidades federais, esperamos diferentes impactos da Lei em cada estado. 
A partir dos editais de vestibular de cada uma das universidades públicas de ambos estados no período anterior e posterior à Lei, observamos onde e quais mudanças de fato ocorreram com a LC. Em Minas Gerais, antes de 2013, 8 universidades federais possuíam algum tipo de ação afirmativa ${ }^{14}$. Apenas em uma universidade ${ }^{15}$ a definição do grupo beneficiário era o mesma que o definido pela LC. Nas outras 7 instituições, para se beneficiar o aluno deveria ter cursado todo o ensino médio e entre 50 e 100\% do ensino fundamental em instituições públicas de ensino. Já nas universidades estaduais, desde 2004 cerca de $40 \%$ das vagas são reservadas para alunos provenientes de famílias com renda inferior à 1,5 s.m.(deste percentual, cerca de $20 \%$ são destinadas para alunos negros e o restante para alunos oriundos de escolas públicas). Em São Paulo, 2 das 3 universidades federais presentes no estado, UFSCAR e UFABC, adotavam, antes da LC, AA para alunos provenientes de escolas públicas. O grupo beneficiário era semelhante ao da LC, alunos que estudaram apenas o ensino médio em escola pública, e portanto a incorporação da LC não representa uma mudança institucional significativa. Das três universidades estaduais paulistas, USP e Unicamp adotam política de bônus ${ }^{16}$. Na Unicamp a política é destinada a alunos autodeclarados pretos, pardos ou indígenas que tenham cursado o ensino médio integralmente em escola pública. A política de bônus da Unicamp teve início em 2003 e não sofreu nenhuma alteração significativa em 2012. Já a USP implementou em 2006 uma política de bônus semelhante à da Unicamp, que também não sofreu alteração em 2012.

Observamos então que, em Minas Gerais, A LC representa uma mudança institucional na medida que, para se beneficiar da reserva de vagas, o aluno precisa cursar apenas as três séries do ensino médio em escola da rede pública. Antes de 2013, alunos matriculados no último ano do ensino fundamental em escola da rede privada e que estudaram os últimos 4 anos em escola privada não poderiam se beneficiar com a mudança para rede pública no primeiro ano do ensino médio. Em uma primeira análise, classificaremos como

São elas: UFTM, UFV, UFOP, UFJF, UFSJ, UFMG, UFVJM e UFU UFOP

16 Nas políticas de bônus, os candidatos beneficiados recebem um acréscimo em sua nota no vestibular, diferentemente das políticas de cotas, em que há uma reserva explítica de vagas para um certo grupo beneficiário. 
tratado pela Lei um aluno que estude apenas o último ano do EF em escola privada em 2012. Contudo, um aluno que tenha estudado 5 anos do EF em escola pública poderia se beneficiar de AA antes da implementação da LC, e portanto receberia o tratamento em dois períodos. Apesar de apenas cerca de $5 \%$ dos alunos que estudaram o último ano do EF em escola privada terem estudado os últimos 4 anos em escola pública, realizaremos um teste de robustez utilizando os alunos que estudaram os últimos 3 anos em escolas da rede privada ${ }^{17}$. Por outro lado, em São Paulo, a Lei de Cotas não representa uma alteração significativa no acesso ao ensino superior, já que a maior parte das vagas IES públicas do estado estão em instituições estaduais, que não sofreram alterações em suas políticas de bônus em 2012, e as universidades federais já tinham AA com público beneficiário semelhante ao da Lei de Cotas.

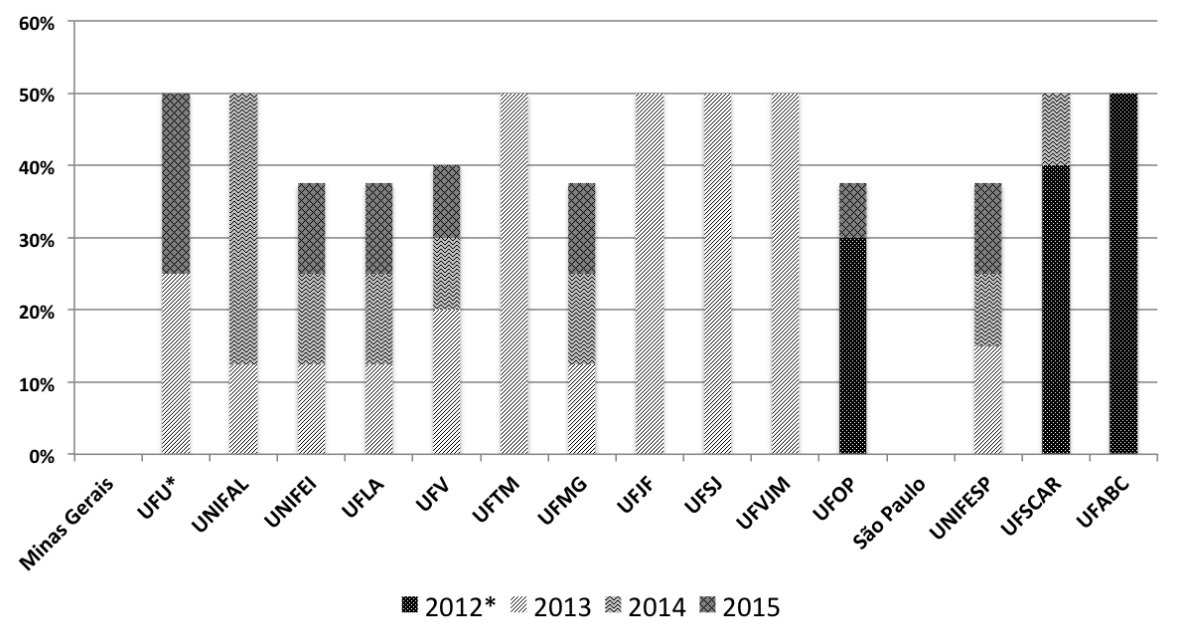

Figura 3 - Percentual de vagas reservadas para alunos que estudaram o EM integralmente na rede pública

Notas: A Lei de Cotas entra em vigor no primeiro vestibular de 2013. Alguma intituições adotam o mínimo de vagas para 2016, 50\%, já em 2013, como é o caso da UFJF, UFSJ e UFVJM. Em 2012, a tabela aprensenta apenas o percentual de vagas para as AA que tinham o mesmo grupo beneficiário que a Lei de Cotas. Fonte: Edital dos vestibulares.

Já no primeiro vestibular de 2013, todas as universidades federais são obrigadas a reservar no mínimo $12.5 \%$ das vagas para alunos que cursaram o EM integralmente na rede pública. Observamos na figura 3 que, em São Paulo, apenas a UNIFESP amplia já

17 Como o Censo Escolar passa a oferecer dados a nível individual e com abrangência populacional apenas a partir de 2007, conseguimos apenas observar os alunos matriculados nas coorte de 2011 nos últimos 3 anos. 
em 2013 o percentual de vagas reservadas, pois, nas outras duas instituições do estado, ações afirmativas com o mesmo grupo beneficiário estavam em vigor no período anterior à Lei e não sofreram alterações. Em Minas Gerais, todas as instituições ampliam ou adotam a reserva de vagas para alunos da rede pública, exceto a UFOP, que já possuia AA com grupo beneficiário semelhante ao da Lei de Cotas e não amplia o percentual de vagas reservados em 2013.

Observamos então uma mudança na definição do grupo beneficiário para praticamente todas as universidades de Minas Gerais, além de uma expansão no percentual de vagas para reservadas nas federais que adotam políticas mais tímidas antes de 2012. Essa expansão ocorre não apenas em 2013, mas nos vestibuares de 2014 e 2015, indicando que o impacto da Lei pode se estender para coortes posteriores à 2012. Em São Paulo, a mudança ocorre em menor grau. Duas das três federais no estado já reservavam mais de $40 \%$ das vagas para o mesmo grupo beneficiário especificado pela Lei de Cotas. Ainda, a única universidade que apresenta grupo diferenciado, UNIFESP, opta por adotar percentual próximo ao mínimo em 2013, reservando apenas 15\% de suas vagas para a LC. 
Tabela 2 - Ações afirmativas implementadas antes da Lei de Cotas

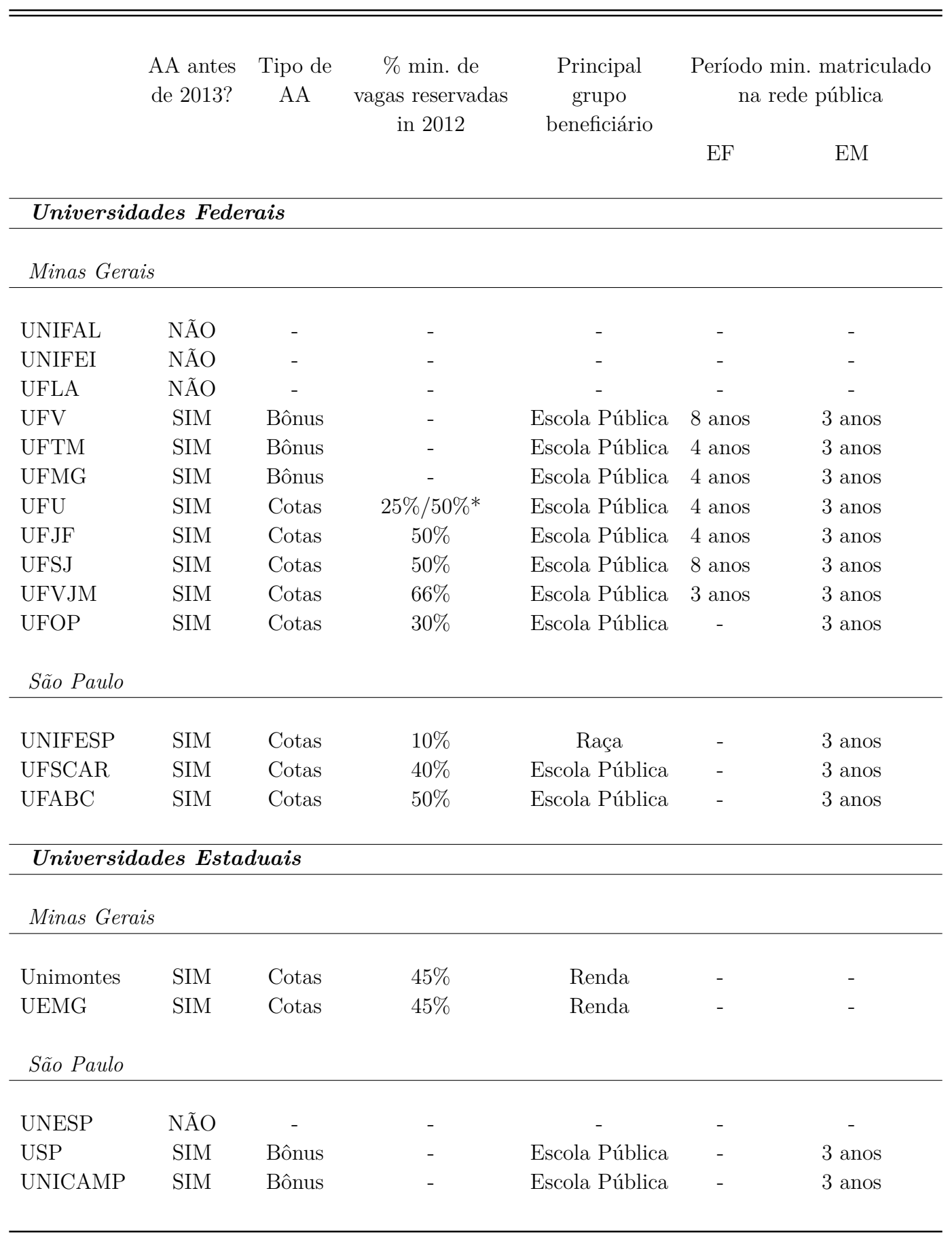

* Na UFU, $25 \%$ das vagas dos cursos com entrata semestral eram destinadas a alunos que cursaram os últimos quatro anos do EF e os EM integralmente na rede pública. Já nos cursos com entrada anual, o percentual de vagas reservadas era de $50 \%$.

Fonte: Edital dos vestibulares 


\section{Revisão de Literatura}

Esta revisão de literatura está dividida em duas subseções. Primeiramente analisaremos os trabalhos que versam sobre o impacto de AA, em especial as de caráter color-blind, sobre os alunos de EM. Em seguida, buscamos compreender os determinantes que levam as famílias a matricular seus filhos em instituições privadas de ensino.

\subsection{Ações Afirmativas e a Escolha de Escola}

O termo "color-blind affirmative action", usado por Fryer, Loury e Yuret (2003), refere-se a AA que não tomam a raça como fator principal para definição do grupo beneficiário. Este tipo de política surgiu em alguns estados do E.U. em resposta a decisões judiciárias que proibiam a adoção de políticas do tipo "color-sighted", ou seja, que beneficiavam explicitamente alunos negros. Os estados do Texas, Florida e Califórnia implementaram então políticas conhecidas como "percentege plans", em que uma determinada porcentagem dos melhores alunos de todas as escolas públicas do estado tinham vaga garantida em uma universidade estadual. No caso do Texas, foi aprovadas a House Bill 588, que garantia vaga nas universidades estaduais para todos os alunos que se graduassem entre os dez por cento melhores de sua escola. Indiretamente, esta Lei acabou criando um incentivo para que alunos ligeiramente abaixo do threshold de dez por cento em sua escola mudassem para uma escola com rendimento inferior.

A fim de analisar este efeito, Estevan et al. (2012) utilizam a metodologia de Diferenças-em-Diferenças para estimar o impacto da "Top-ten Percent Law" na segregação étnica nas escola de EM do Texas. A análise empírica encontra evidências de redução na segregação nas duas últimas séries do EM em relação ao $9^{\circ}$ ano do EF, não afetado pela Lei. Observa-se a migração de alunos de escolas de mais alto rendimento, que possuem uma menor quantidade de alunos subrepresentados, para escolas de mais baixo rendimento nos últimos anos do EM. Ainda, os autores encontram que os estudantes que estão mais inclinados a mudar para uma escola de mais baixo rendimento são aqueles que não estão 
em desvantagem financeira.

Em outro trabalho empírico abordando o mesmo tema, Cullen, Long e Reback (2013) encontram resultados similares. Utilizando um modelo de logit condicional com base em dados a nível individual, os autores analisam a escolha de escola de EM dos alunos matriculados no último ano do EF no período anterior e posterior à Lei, a fim de identificar possíveis mudanças no padrão de escolha. Estima-se que entre 5 e $25 \%$ dos alunos que tem tanto motivo, baseado em suas notas na $8^{a}$ série, e oportunidade, baseado na existência de mais de uma escola de EM em seu bairro, mudam de escola em resposta à Lei.

Esses dois trabalhos encontram evidências de que políticas que asseguram benefícios no acesso ao ensino superior a um grupo específico de escolas, podem levar a um comportamento estratégico por parte dos alunos de escolas não beneficiadas. Isso se torna mais evidente quando não há barreiras no acesso às escolas do grupo beneficiado, como é, em geral, o caso das escolas públicas e gratuitas no Brasil. No caso da LC, este tipo de resposta estratégica pode levar a um aumento da migração de alunos de escolas privadas para escolas da rede pública a partir do $1^{a}$ série do EM.

Contudo, apesar dos incentivos similares envolvidos, nenhum trabalho analisando o impacto da LC sobre a escolha da rede de escolas foi realizado utilizando dados brasileiros. Enquanto alguns estudos estimam o efeito de AA no esforço dos alunos ${ }^{18}$ e taxa de ingresso nas universidades brasileiras, outros analisam diferentes medidas de impacto na eficiência das universidades que aderem a $\mathrm{AA}^{19}$.

18 Ferman e Assuncao (2005) e Francis e Tannuri-Pianto (2012) analisam o impacto de cotas raciais implementadas nos estados da Bahia e do Rio de Janeiro nas notas dos alunos do grupo beneficiário no ENEM. Os estudos encontram resultados divergentes, indicando que AA podem tanto aumentar ou diminuir o esforço dos alunos do grupo beneficiário, dependendo da proporção de vagas reservadas.

19 Fryer, Loury e Yuret (2003) desenvolvem um modelo teórico para compreender o efeito de leis do tipo "color-blind" no processo de admissão das universidades. O modelo adotado sugere que "color-blind affirmative actions" são menos eficientes que "color-sighted". 


\subsection{Determinantes da Escolha de Escola}

Como o objetivo deste trabalho é identificar se a LC está relacionada a um aumento na probabilidade de migração para rede pública, é essencial saber quais os principais fatores que determinam a escolha de uma família em matricular seu(s) filho(s) em uma escola privada.

Em um dos primeiros trabalhos a tratar empiricamente sobre o tema, Long e Toma (1988) utilizam dados do Censo americano de 70 e 80 para identificar os determinantes da escolha por escola privada. Com base em um modelo de probabilidade linear, os autores encontram que a renda familiar, afiliação religiosa e oferta de escolas privadas no munícipio afetam positivamente a probabilidade de um aluno estar matriculado na rede privada. A fim de estimar os determinantes dessa mesma escolha, Menezes-Filho, Curi et al. (2011), a partir de dados da PNAD e da POF e utilizando modelos para dados censurados, estimam que a educação da mãe, a renda familiar, e a oferta e custo das escolas privadas no munícipio do aluno afetam positivamente a probabilidade de matricula na rede privada.

Opice (2015) parte de um modelo de probabilidade linear com base em dados individuais de alunos do estado de São Paulo, para identificar as variáveis associadas à probabilidade de migração da rede pública para privada no fim dos dois ciclos do EF, ou seja, $5^{\circ}$ e $9^{\circ}$ ano. A autora encontra que educação da mãe, renda familiar e a nota do aluno em uma prova padronizada impactam positivamente a probabilidade de migração para rede privada. Observa-se ainda que alunos brancos e matriculados em escolas públicas melhores tem maior probabilidade de migrar para rede privada no ano seguinte.

Em relação ao mercado de escolas privadas, o trabalho seminal de Epple e Romano (1998) desenvolve um modelo teórico com o objetivo de encontrar um equilíbrio na alocação entre alunos, diferenciados em renda e habilidade, e escolas públicas e privadas, sendo que as escolas privadas podem descriminar preços. Em equilíbrio, as escolas públicas recebem os estudantes mais pobres e de mais baixa habilidade, enquanto surge uma hierarquia estrita de escolas particulares, gerando segregação dentro do sistema de ensino. 
Menezes-Filho, Moita e Andrade (2014) analisam o impacto de uma política pública que aumenta a participação de alunos mais pobres no sistema de ensino básico, o Bolsa Família. Os autores apontam que esta política aumenta a desigualdade educacional dentro do sistema publico de ensino, já que estimula a entrada de alunos que antes sequer estavam na escola. Estima-se que o aumento na desigualdade educacional está relacionado a um aumento na probabilidade de entrada de uma escolar privada em dado munícipio, pois alguns alunos do sistema público passam a demandar uma alternativa privada em decorrência da queda na qualidade do ensino.

Por fim, outro fator que pode afetar a decisão de escolha pela rede privada é a qualidade das escolas públicas no município da família. Estevan (2014) analisa o impacto de um aumento exógeno nos gastos municipais com educação pública sobre a parcela de alunos do $1^{o}$ ciclo do EF matriculados na rede privada de ensino. Os resultados indicam que o aumento nos gastos reduz a matricula na rede privada ${ }^{20}$. Epple, Figlio e Romano (2004), a partir de um painel com 15590 estudantes americanos, encontram que a renda familiar e a habilidade de um aluno influenciam positivamente a probabilidade de matricula em escola privada. O trabalho aponta também que, em municípios onde os gastos com educação pública são menores, o impacto da renda sobre a probabilidade de matricula na rede privada é superior.

Apesar de não haver trabalho que trate sobre a migração da rede privada para rede pública, a literatura de school choice aponta para algumas variáveis: educação da mãe, renda familiar, habilidade do aluno, oferta e custo das escolas privadas e qualidade das escolas públicas no município do aluno.

20 Em outro trabalho, Estevan (2009) mostra que este aumento exógeno de gastos está relacionado à melhora em indicadores de qualidade das escolas. 


\section{Método de Identificação}

O principal objetivo empírico deste trabalho é identificar se a Lei de Cotas aumenta a probabilidade de migração para a rede pública, isto é, se a Lei tem algum impacto sobre a escolha de escola dos alunos brasileiros matriculados em escolas privadas. Neste contexto, os alunos tratados pela Lei são aqueles que podem se beneficiar na disputa por uma vaga em uma universidades federais ao mudar de escola. Como a Lei vale para aqueles que estudaram apenas o EM integralmente na rede pública, consideramos que os alunos afetadas são aqueles matriculados no último ano do EF em escola da rede privada.

Como já discutido, os dados disponibilizados pelo Censo Escolar não fornecem informações socioeconômicas acerca das variáveis que influenciam a decisão de migração. Para contornar essa limitação e obter um método de identificação consistente, utilizaremos a metodologia de Diferenças-em-Diferenças (DD).

Consideraremos que um aluno matriculado em escola privada só realiza a escolha de se manter no sistema privado ou migrar para o sistema público uma vez por ano, ao fim do ano letivo. Para observar a variação na probabilidade de migração para rede pública de alunos matriculados em alguma etapa do ensino básico, observaremos coortes de alunos matriculados nesse segmento em anos posteriores e anteriores à implementação da Lei.

Realizaremos duas análises, uma utilizando apenas as coortes de 2011 e 2012, isto é, o período imediatamente anterior e posterior à implementação da Lei, e, em uma segunda análise, utilizando todas as coortes disponíveis, 2009, 2010, 2011, 2012, 2013 e 2014, totalizando 3 coortes não afetadas e 3 coortes afetadas pela LC. Os grupos de tratamento são compostos pelos alunos matriculados no $9^{\circ}$ ano do EF em escolas da rede privada em cada uma das coortes analisadas. A LC entra em vigor em 2012 e já vale para o primeiro vestibular de 2013, portanto todos os alunos do grupo de tratamento matriculados em escola privada nas coortes de 2012, 2013 e 2014 são afetados pela Lei. Já os grupos de controle são compostos por alunos matriculados no $5^{\circ}$ ano do EF. Assim como o $9^{\circ}$ ano, o $5^{\circ}$ ano também representa um final de ciclo e, portanto, o custo de 
mudança de rede é semelhante ${ }^{21}$. Contudo, os alunos do $5^{\circ}$ ano não são afetados pela Lei, já que a LC beneficia aqueles que estudaram apenas o EM na rede pública e, portanto, a decisão de migrar ou não para rede pública no ano seguinte não irá definir se serão beneficiados. Temos como hipótese que alunos matriculados no $5^{\circ}$ que tenham a intenção de migrar para escola pública no EM a fim de beneficiarem-se da Lei, não irão antecipar essa migração já no $6^{\circ}$ em decorrência do grande diferencial de qualidade entre as redes de ensino no Brasil, descrito na seção anterior.

Definiremos a função estrutural que modela a probabilidade de um aluno matriculado em uma escola particular em um dado ano migrar para uma escola pública no ano seguinte como:

$$
Y_{i s t}=\alpha \cdot a n o_{t}+\beta \cdot \operatorname{trat}_{s}+\theta \cdot\left(\text { ano }_{t} \cdot \text { trat }_{s}\right)+\Gamma \cdot X_{i s t}+u_{i s t}
$$

Onde $Y_{i s t}$ é uma variável binária que vale 1 se o aluno $i$ do grupo $s$ no ano $t$ muda para escola pública no ano $t+1$ e 0 caso contrário. $X_{i s t}$ é um vetor contendo todas as variáveis que influenciam a decisão de migração para escola pública. $\theta$ é nosso coeficiente de interesse.

Com base nos resultados apresentados pela literatura, iremos considerar que o vetor $X_{i s t}$ contém as seguintes variáveis: renda familiar per capita, número de irmãos, educação dos pais, qualidade das escolas públicas e oferta relativa de escolas privadas no município do aluno $i$ no ano $t$, custo da educação privada e outras variáveis não observáveis que não se alteram no tempo. Como a maior parte dessas variáveis não estão disponíveis na base de dados utilizada, controlaremos apenas pela qualidade das escolas públicas e oferta relativa de escolas privadas no município do aluno $i$ no ano $t$.

A primeira especificação a ser estimada não levará em consideração nenhuma das

$\overline{21}$ Estevan (2014) encontra evidências de que um aumento exógeno nos gastos com educação pública reduz a parcela de alunos matriculados em escolas privadas no $1^{\circ}$ ano do EF relativamente aos 3 anos subsequentes, indicando que há custos diferenciados de mudança de escola entre anos finais de ciclo e os outros anos. 
variáveis de controle mencionadas acima.

$$
Y_{i s t}=\alpha \cdot \text { ano }_{t}+\beta \cdot \text { trat }_{s}+\theta \cdot\left(\text { ano }_{t} \cdot \text { trat }_{s}\right)+u_{i s t}
$$

Incluindo a nota no IDEB das escolas públicas ${ }^{22}$ e a razão entre o número de escolas privadas e públicas de EM no munícipio do aluno $i$ no ano $t$, variáveis de controle para a qualidade da escola pública e oferta de escolas privadas, chegamos à segunda especificação a ser estimada:

$$
Y_{i s t}=\alpha \cdot a n o t_{t}+\beta \cdot \operatorname{trat}_{s}+\theta \cdot\left(\text { ano }_{t} \cdot \text { trat }_{s}\right)+\gamma \cdot I D E B_{i s t}+\phi \cdot O R_{i s t}+u_{i s t}
$$

Por fim, serão realizadas análises incluindo características socioeconômicas para o município do aluno ${ }^{23}$ e erros clusterizados por escola/ano, terceita e quarta especificação respectivamente. A segunda análise será feita por dois motivos: i) a decisão de um aluno (ou um grupo de alunos) que muda de turma pode ter impacto sobre a decisão de seus colegas de sala, acarretando em correlação entre os erros individuais ${ }^{24}$; ii) fatores exógenos que afetem uma escola em determinado ano, podem afetar a decisão de migração de todos os alunos dessa escola.

\subsection{Hipóteses de Identificação}

Partindo de qualquer uma das especificações a serem estimadas, temos como condição necessária para identificação que qualquer variação na probabidade de migração decorrente de mudanças em variáveis não observáveis ocorra em igual magnitude para o grupo de controle e tratamento. Se um aumento na renda familiar dos alunos de $9^{\circ}$, por

22 Como o IDEB é realizado a cada 2 anos, para as coortes de 2014 foi considerada a nota de 2013, para as coortes de 2013 e 2012 a nota de 2011, para as coortes de 2011 e 2010 a nota de 2009 e para as coortes de 2009 a nota de 2007. Incluímos o IDEB defasado, pois as famílias apenas tem conhecimento do índice em seu município no ano posterior à realização da Prova Brasil. Dessa forma, o IDEB de 2011, por exemplo, apenas é observado pelas famílias em 2012.

23 As variáveis utilizadas foram o coeficiente de gini, percentual da população em situação de pobreza, renda per capita, população total e o a qualidade da educação pública medida pelo IDHM, disponíveis no Censo 2010.

24 Como as turmas são em geral pequenas e a correlação entre as características de alunos de uma mesma turma é muito alta, não iremos clusterizar os erros à nível da turma, pois isso tornaria qualquer estimador estatistiscamente não signficante. 
exemplo, levar a uma queda na probabiliadde de migração desse grupo, é necessário que também ocorra o aumento na renda dos alunos do grupo de controle e que o impacto sobre a probabilidade de migração ocorra em igual magnitude. Definimos formalmente essa condição como:

$$
\begin{aligned}
& \left\{E\left[Y_{i s t} \mid X_{i s t}, s=1, t=1\right]-E\left[Y_{i s t} \mid X_{i s t}, s=1, t=0\right]\right\}- \\
& \left\{E\left[Y_{i s t} \mid X_{i s t}, s=0, t=1\right]-E\left[Y_{i s t} \mid X_{i s t}, s=0, t=0\right]\right\}=\theta
\end{aligned}
$$

O que nos leva à hipótese de identificação:

$$
\begin{aligned}
& E\left[u_{i s t} \mid X_{i s t}, s=1, t=1\right]-E\left[u_{i s t} \mid X_{i s t}, s=1, t=0\right]= \\
& E\left[u_{i s t} \mid X_{i s t}, s=0, t=1\right]-E\left[u_{i s t} \mid X_{i s t}, s=0, t=0\right]
\end{aligned}
$$

Caso a hipótese de identificação seja válida, os estimadores de DD para a regressão (4.1) serão consistentes e não viesados. Quando analisamos apenas as coortes imediatamente anterior e posterior à implementação da Lei, é condição suficiente que todas as variáveis incluídas no vetor $X_{i s t}$ e que não estão especificadas na equações (1) a (4), entre elas: renda familiar per capita, número de irmãos, educação dos pais e custo da educação privada; não variem significativamente de 2011 para 2012.

Com base na informações da PNAD, observamos que essa condição é satifisfeita tanto para as coortes de São Paulo, quanto de Minas Gerais, como pode ser obserado na tabela abaixo. Vale ressaltar que, diferentemente do Censo Escolar, as informações presentes na PNAD são amostrais, motivo pelo qual o número de observações na análise abaixo é muito inferior ao total de alunos observados nas coortes de controle e tratamento. 
Tabela 3 - Testes de média das características socioeconômicas

\begin{tabular}{|c|c|c|c|c|c|c|c|c|}
\hline & \multicolumn{4}{|c|}{ Tratamento } & \multicolumn{4}{|c|}{ Controle } \\
\hline & 2011 & 2012 & Dif. & p-val. & 2011 & 2012 & Dif. & p-val. \\
\hline \multicolumn{9}{|l|}{ Minas Gerais } \\
\hline Renda per capita & 1459,69 & 1862,78 & 403,09 & 0,14 & 1627,46 & 1433,02 & $-194,44$ & 0,48 \\
\hline \# pessoas na família & 3,88 & 3,81 & $-0,06$ & 0,73 & 3,68 & 3,59 & $-0,08$ & 0,67 \\
\hline \# anos de estudo da P.R* & 14,37 & 14,30 & $-0,06$ & 0,89 & 14,27 & 14,85 & 0,57 & 0,15 \\
\hline Obs. & 54 & 74 & & & 49 & 48 & & \\
\hline \multicolumn{9}{|l|}{ São Paulo } \\
\hline Renda per capita & 1635,38 & 1745,42 & 110,03 & 0,61 & 1573,21 & 1691,60 & 118,38 & 0,68 \\
\hline \# pessoas na família & 3,85 & 4,07 & 0,21 & 0,14 & 3,91 & 3,82 & 0,97 & 0,48 \\
\hline \# anos de estudo da P.R* & 15,50 & 15,38 & $-0,12$ & 0,58 & 15,61 & 15,47 & $-0,19$ & 0,30 \\
\hline Obs. & 90 & 91 & & & 82 & 84 & & \\
\hline
\end{tabular}





\section{Dados}

Para identificar a migração de alunos da rede privada para rede pública, utilizaremos os dados presentes no Censo Escolar. Desde 2007, esta base fornece informações a nível individual de todos os alunos matriculados no ensino básico em escolas públicas ou privadas. Por meio de um código de identificação é possível acompanhar a escola e turma em que um aluno está matriculado e, com isso, saber se em algum momento este aluno tomou a decisão de migrar de rede. Também utilizaremos dados do Censo Escolar para a construção da varíavel $O R_{i s t}$, que representa a razão entre escolas privadas e públicas de EM no munícipio do aluno $i$ no ano $t$, e para construção das variáveis utilizadas na seção de heterogeniedade.

Tabela 4 - Número de alunos por coorte de controle e tratamento

\begin{tabular}{cccccc} 
& \multicolumn{2}{c}{ Minas Gerais } & & \multicolumn{2}{c}{ São Paulo } \\
\cline { 2 - 3 } \cline { 5 - 6 } & Controle & Tratamento & & Controle & Tratamento \\
\hline \hline $\mathbf{2 0 1 4}$ & 29715 & 27628 & & 106118 & 105326 \\
$\mathbf{2 0 1 3}$ & 28469 & 27630 & & 101310 & 106107 \\
$\mathbf{2 0 1 2}$ & 27818 & 27549 & & 100309 & 101860 \\
$\mathbf{2 0 1 1}$ & 28032 & 27292 & & 96894 & 100196 \\
$\mathbf{2 0 1 0}$ & 27373 & 26694 & & 97359 & 95419 \\
$\mathbf{2 0 0 9}$ & 26991 & 26087 & & 98768 & 92013 \\
\hline \hline
\end{tabular}

Para construção de estatísticas descritivas e análise da validade da hipótese de identificação, utilizamos dados da Pesquisa Nacional por Amostra de Domicílio (PNAD), mais especificamente as informações referentes à renda familiar per capita, número de pessoas na família e número de anos de instrução da pessoa de referência na família ${ }^{25}$. Utilizaremos também os dados do Censo 2010 para construção das variáveis socioeconômicas dos munícipios, que servirão como controle na análise empírica, e informações do IDEB a nível municipal a fim de construir um indicador de qualidade das escolas públicas.

25 Pessoa responsável pela família ou que assim fosse considerada pelos demais membros da família. Variável utilizada como proxy para anos de estudo de um dos pais. 


\subsection{Atrito}

Definiremos atrito como os alunos que são observados no Censo em um ano, mas não são encontrados no ano seguinte. Esse problema pode ocorrer por uma das seguintes razões: i) evasão escolar; ii) mudança do aluno para outro país; iii) erro cadastral por parte da escola, o que impossibilita a identicação de um aluno no painel. Em relação ao motivo (i), a tabela (5) apresenta as taxas de evasão para os grupos de controle e tratamento ao longo das coortes analisadas. Observamos que a taxa é extratamente baixa para os alunos provenientes de escolas privadas e não se altera radicalmente entre as coortes 2011 e 2012 . O problema (ii) será desconsiderado, partindo da hipótese de que não há correlação entre a variação na migração para o exterior e o período de implementação da Lei de Cotas.

Neste trabalho, o atrito pode ser um problema para a identificação caso o problema (iii) esteja correlacionado com a implementação da Lei. Supomos que a probalidade de erro cadastral é maior quando o aluno muda de escola. Dessa forma, com o aumento da migração no período em que a Lei de Cotas entra em vigor, deverá haver um aumento na quantidade de atrito, especialmente no grupo mais afetado pela Lei. Contudo, note que este problema tornaria nossos estimadores mais conservadores, já que no caso onde a variação na probabilidade de migração para rede pública é maior para o grupo de tratamento, esperamos que uma parte dos alunos do grupo de tratamento tenham desaparecido da base em decorrência da mudança do código de identificação. Assim, a variação observada será inferior à variação efetiva. Como não temos como recuperar os alunos pedidos devido a essa forma de atrito, iremos desconsiderar este possível problema em nossa análise ao custo de estimar mais conservadoramente o impacto da Lei, nos casos em que ele exista. 
Tabela 5 - Reprovação e abandono escolar por coorte de controle e tratamento- Minas Gerais e São Paulo

\begin{tabular}{|c|c|c|c|c|c|c|c|}
\hline \multicolumn{2}{|c|}{ 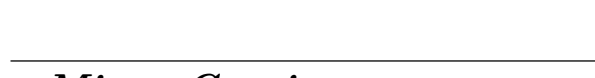 } & 2014 & 2013 & 2012 & 2011 & 2010 & 2009 \\
\hline \multicolumn{8}{|c|}{ Minas Gerais } \\
\hline \multirow{2}{*}{ Tratamento } & Abandono escolar & $0,4 \%$ & $0,5 \%$ & $0,5 \%$ & $0,5 \%$ & $0,5 \%$ & $0,6 \%$ \\
\hline & Taxa de reprovação & $5,2 \%$ & $5,8 \%$ & $5,8 \%$ & $6,3 \%$ & $5,6 \%$ & $5,9 \%$ \\
\hline \multirow{2}{*}{ Controle } & Abandono escolar & $0,1 \%$ & $0,0 \%$ & $0,1 \%$ & $0,1 \%$ & $0,1 \%$ & $0,1 \%$ \\
\hline & Taxa de reprovação & $1,5 \%$ & $1,6 \%$ & $1,6 \%$ & $1,7 \%$ & $1,7 \%$ & $1,8 \%$ \\
\hline \multicolumn{8}{|l|}{ São Paulo } \\
\hline \multirow{2}{*}{ Tratamento } & Abandono escolar & $0,1 \%$ & $0,1 \%$ & $0,2 \%$ & $0,2 \%$ & $0,2 \%$ & $0,2 \%$ \\
\hline & Taxa de reprovação & $2,9 \%$ & $3,3 \%$ & $3,2 \%$ & $3,4 \%$ & $3,3 \%$ & $3,5 \%$ \\
\hline \multirow{2}{*}{ Controle } & Abandono escolar & $0,0 \%$ & $0,0 \%$ & $0,0 \%$ & $0,0 \%$ & $0,0 \%$ & $0,0 \%$ \\
\hline & Taxa de reprovação & $1,3 \%$ & $1,4 \%$ & $1,4 \%$ & $1,5 \%$ & $1,7 \%$ & $1,7 \%$ \\
\hline
\end{tabular}





\section{Resultados}

Na tabela (6) são apresentados os coeficientes de interesse estimados para todas as especificações apresentadas. Os resultados estão dividos por estado, Minas Gerais e São Paulo, e foram escolhidos dois períodos para análise. No primeiro, foram considerados apenas duas coortes, uma imediatamente anterior à implementação da Lei (2011), portanto não afetada, e outra relativa ao ano de sanção da Lei (2012). No segundo, são utilizadas seis coortes, três não afetadas (2009,2010 e 2011) e três afetadas pela Lei (2012, 2013 e 2014).

Em Minas Gerais, o impacto da Lei sobre a migração para rede pública é positivo e estatiscamente significante à 1\% para todas as especificações analisadas. Quando analisado dois períodos, observamos que a Lei aumenta em cerca de 2.2 p.p a probabilidade de migração para rede pública na $1^{\mathrm{a}}$ série do EM, o que representa uma variação de $20 \%$ em relação a probabilidade de migração do grupo de tratamento no período anterior à Lei. Já nas regressões em que são utilizados 6 períodos, e que portanto incorporam os impactos da Lei nos 3 anos posteriores à sua implementação, o coeficiente estimado sinaliza aumento de cerca de 4.3 p.p na probabilidade de migração.

Já em São Paulo, estado onde a Lei de Cotas não representa uma mudança institucional tão significativa no acesso ao ensino superior, os coeficientes estimados são menores em magnitude e perdem a significancia estatística quando analisados seis períodos. No primeiro caso, observamos que a Lei aumenta em cerca de 1.2 p.p a probabilidade de migração, variação de $8 \%$ em relação à probabilidade observada antes da Lei. Quando incorporamos novas coortes na análise, o coeficiente de interesse cai para 0.1 p.p, e perde a significancia para todas as expecificações.

As váriaveis de controle, IDEB e OFERTA, apresentam resultado negativo e estatisticamente significante para todas as especificações, como pode ser observado na tabela A1, no apêndice. Os resultados confirmam a hipótese de que maior qualidade da educação pública e maior oferta de escolas privadas no município do aluno reduzem a 
probabiliadde de migração para rede pública.

Foi ressaltado na seção anterior que, em Minas Gerais, alunos que estudaram o último ano do EF em escola da rede privada, mas que cursaram ao menos quatro anos na rede pública, poderiam se beneficiar de uma das 6 ações afirmativas em vigor no estado no período anterior à Lei de Cotas. Dessa forma, parcela das alunos de $9^{\circ}$ ano estariam sendo tratados tanto no período posterior, quando no período anterior à Lei de Cotas. Para mitigar essa possibilidade, iremos estimar novamente os coeficientes apresetados na tabela 8, contudo considerando como grupo de tratamento e controle os alunos que estudaram o $9^{\circ}$ e $5^{\circ}$ ano do EF na rede privada, respectivamente, e que estudara os últimos três anos na rede pública ${ }^{26}$. Os resultados apresentados na tabela (7) indicam que, em Minas Gerais, a Lei tem impacto de 1.9 p.p. na probabilidade de migração e, em São Paulo, de 0.9 p.p.

$\overline{26}$ Consideramos três e não quatro anos por uma limitação na base de dados disponível. 
Tabela 6 - Impacto da Lei de Cotas sobre a escolha de escola

\begin{tabular}{|c|c|c|c|c|c|c|c|c|}
\hline & \multicolumn{4}{|c|}{$\begin{array}{c}\text { Duas coortes } \\
(2011-2012)\end{array}$} & \multicolumn{4}{|c|}{$\begin{array}{l}\text { Seis coortes } \\
(2009-2014)\end{array}$} \\
\hline & (1) & $(2)$ & (3) & (4) & (1) & $(2)$ & (3) & (4) \\
\hline \multicolumn{9}{|c|}{ Painel A: Minas Gerais } \\
\hline Lei de Cotas & $\begin{array}{c}0.022^{* * *} \\
(0.004)\end{array}$ & $\begin{array}{c}0.022^{* * *} \\
(0.004)\end{array}$ & $\begin{array}{c}0.022^{* * *} \\
(0.004)\end{array}$ & $\begin{array}{c}0.022^{* * *} \\
(0.005)\end{array}$ & $\begin{array}{c}0.045^{* * *} \\
(0.002)\end{array}$ & $\begin{array}{c}0.039 * * * \\
(0.002)\end{array}$ & $\begin{array}{c}0.039 * * * \\
(0.002)\end{array}$ & $\begin{array}{c}0.039 * * * \\
(0.004)\end{array}$ \\
\hline Obs. & 110691 & 110543 & 110543 & 110543 & 331278 & 330955 & 330955 & 330955 \\
\hline$R^{2}$ & 0.004 & 0.014 & 0.022 & 0.022 & 0.004 & 0.015 & 0.022 & 0.022 \\
\hline \multicolumn{9}{|l|}{ Painel B: São Paulo } \\
\hline Lei de Cotas & $\begin{array}{c}0.012^{* * *} \\
(0.002)\end{array}$ & $\begin{array}{c}0.012^{* * *} \\
(0.002)\end{array}$ & $\begin{array}{c}0.012^{* * *} \\
(0.002)\end{array}$ & $\begin{array}{c}0.012^{* *} \\
(0.005)\end{array}$ & $\begin{array}{c}0.001 \\
(0.001)\end{array}$ & $\begin{array}{c}0.001 \\
(0.001)\end{array}$ & $\begin{array}{c}0.001 \\
(0.001)\end{array}$ & $\begin{array}{c}0.001 \\
(0.003)\end{array}$ \\
\hline Obs. & 399259 & 399259 & 399259 & 399259 & 1201679 & 1126743 & 1126743 & 1126743 \\
\hline$R^{2}$ & 0.040 & 0.043 & 0.044 & 0.044 & 0.041 & 0.043 & 0.045 & 0.045 \\
\hline Variáveis de controle & & SIM & SIM & SIM & & SIM & SIM & SIM \\
\hline Carac. municipais & & & SIM & SIM & & & SIM & SIM \\
\hline Erros clusterizados & & & & SIM & & & & SIM \\
\hline
\end{tabular}


Tabela 7 - Impacto da Lei de Cotas sobre a escolha de escola - Alunos que estudaram os últimos 3 anos em escolas privadas

\begin{tabular}{|c|c|c|c|c|}
\hline & \multicolumn{4}{|c|}{$\begin{array}{c}\text { Duas coortes } \\
(2011-2012)\end{array}$} \\
\hline & (1) & $(2)$ & (3) & (4) \\
\hline \multicolumn{5}{|c|}{ Painel A: Minas Gerais } \\
\hline Lei de Cotas & $\begin{array}{c}0.019^{* * *} \\
(0.004)\end{array}$ & $\begin{array}{c}0.019 * * * \\
(0.004)\end{array}$ & $\begin{array}{c}0.019 * * * \\
(0.004)\end{array}$ & $\begin{array}{c}0.019 * * \\
(0.008)\end{array}$ \\
\hline Obs. & 79506 & 79316 & 79316 & 79316 \\
\hline$R^{2}$ & 0.005 & 0.014 & 0.019 & 0.019 \\
\hline \multicolumn{5}{|l|}{ Painel B: São Paulo } \\
\hline Lei de Cotas & $\begin{array}{c}0.009^{* * *} \\
(0.002)\end{array}$ & $\begin{array}{c}0.009 * * * \\
(0.002)\end{array}$ & $\begin{array}{c}0.009 * * * \\
(0.002)\end{array}$ & $\begin{array}{c}0.009 \\
(0.005)\end{array}$ \\
\hline Obs. & 310143 & 310143 & 310143 & 310143 \\
\hline$R^{2}$ & 0.046 & 0.048 & 0.050 & 0.050 \\
\hline Variáveis de controle & & SIM & $\mathrm{SIM}$ & SIM \\
\hline Carac. municipais & & & SIM & SIM \\
\hline Erros clusterizados & & & & SIM \\
\hline
\end{tabular}

Notas: Em ambos painéis foi utilizado como grupo de controle os alunos de $5^{\circ}$ ano do EF. A significancia estatistica dos resultados e representada por: *** Estatisticamente significante ao nivel de 1\%, ${ }^{* *}$ Estatisticamente significante ao nivel de $5 \%, *$ Estatisticamente significante ao nivel de $10 \%$ 


\section{Heterogeniedade}

Nos observamos um aumento na probabilidade de migração dos alunos do grupo de tratamento em relação ao grupo de controle, após a implementação da Lei de Cotas, especialmente no estado de Minas Gerais. Cabe analisar se escolas com diferentes níveis de qualidade são afetas hetereogiamente pela Lei.

Como não possuímos informações referentes ao preço da mensalidade de todas as escolas particulares do país ${ }^{27}$ e não há avaliação educacional externa obrigatória para escolas privadas de ensino fundamental e médio em Minas Gerais, utilizaremos dados de infraestrutura e qualidade de corpo docente para construir uma proxy de qualidade das escolas.

Na tabela (8), observamos a percentual de alguns itens de infraestrutura e o percentual médio de professores com pós-graduação nas escolas dos alunos dos grupos de controle e tratamento em Minas Gerais. Como pode ser observado, nas escolas da rede privada, a variação nos itens de infraestrutura é muito baixa, já que a maior parte das escolas possui todos os itens listados no Censo Escolar ${ }^{28}$. Portanto, iremos utilizar apenas duas variáveis para construção de um indicador de qualidade, o número de computadores por aluno e o percentual de professores com pós graduação na escola do aluno $i$.

Tabela 8 - Percentual de escolas por item de infraestrutura e percentual médio de professores com pós graduação

\begin{tabular}{lccccc} 
& \multicolumn{2}{c}{ Minas Gerais } & & \multicolumn{2}{c}{ São Paulo } \\
\cline { 2 - 3 } \cline { 5 - 6 } \cline { 5 - 6 } & Controle & Tratamento & & Controle & Tratamento \\
\hline \hline Biblioteca & $96.47 \%$ & $97.87 \%$ & & $66.67 \%$ & $68.56 \%$ \\
Lab. Ciências & $68.97 \%$ & $84.75 \%$ & & $63.13 \%$ & $68.94 \%$ \\
Lab. Informática & 82.77 & $86.96 \%$ & & $82.05 \%$ & $84.75 \%$ \\
Computadores por aluno & 0.03 & 0.04 & & 0.05 & 0.05 \\
Docentes com pós graduação & $47.59 \%$ & $46.04 \%$ & & $38.20 \%$ & $37.02 \%$ \\
\hline \hline
\end{tabular}

Para estimar a possível heterogeneidade no impacto da Lei, realizaremos duas análises. Primeiramente, incluímos as variáveis que representam o percentual de professores

$27 \quad$ Esta variável seria um bom indicativo para o gasto por aluno em cada escola.

28 Não incluímos outras variáveis de infraestrutura presentes no Censo Escolar nesta análise, pois para maior parte delas a prevalência é quase absoluta no universo de escolas particulares. 
com pós graduação, $P O S_{i s t}$, e o número de computadores por aluno, $C O M P_{i s t}$ na escola do aluno $i$, além das respectivas interações com a variável de interesse. A regressão estimada será:

$$
\begin{aligned}
Y_{i s t}= & \alpha \cdot \text { ano }_{t}+\beta \cdot \text { trat }_{s}+\theta \cdot\left(\text { ano }_{t} \cdot \text { trat }_{s}\right)+ \\
& \gamma \cdot I D E B_{i s t}+\phi \cdot O R_{i s t}+\sigma \cdot \text { POS }_{i s t}+\rho \cdot C O M P_{i s t}+ \\
& \varsigma \cdot\left(\text { POS }_{i s t} \cdot \text { ano }_{t} \cdot \text { trat }_{s}\right)+\varrho \cdot\left(\text { COMP }_{\text {ist }} \cdot \text { ano }_{t} \cdot \text { trat }_{s}\right)+u_{i s t}
\end{aligned}
$$

Em seguida, classificamos as escolas de acordo com quartil em que se encontram na distribuição de $C O M P_{i s t}$ e $P O S_{i s t}$. As variáveis binárias $C O M P 1_{i s t}$ e $P O S 1_{i s t}$ na regressão (5.1) assumirão o valor 1 para as escolas que se encontram no último quartil na distribuição de número de computadores por aluno e de professores com pós-graduação, respectivamente, e 0 caso contrário. Considerando apenas as variáveis observadas, essas serão consideradas as escolas de maior qualidade, representando $26,8 \%$ e 26,9 \% do total de alunos matriculados em Minas Gerais.

$$
\begin{aligned}
Y_{\text {ist }}= & \alpha \cdot \text { ano }_{t}+\beta \cdot \text { trat }_{s}+\theta \cdot\left(\text { ano }_{t} \cdot \text { trat }_{s}\right)+ \\
& \gamma \cdot I D E B_{i s t}+\phi \cdot O R_{i s t}+\sigma \cdot P O S 1_{i s t}+\rho \cdot C O M P 1_{i s t}+ \\
& \varsigma \cdot\left(P O S 1_{i s t} \cdot \text { ano }_{t} \cdot \text { trat }_{s}\right)+\varrho \cdot\left(C O M P 1_{i s t} \cdot \text { ano }_{t} \cdot \text { trat }_{s}\right)+u_{i s t}
\end{aligned}
$$

Os resultados da tabela (9) apontam que, em Minas Gerais e São Paulo, o impacto da Lei de Cotas é menor em escolas com maior percentual de professores com pós graduação, sendo a estimativa estatiscamente significante à $5 \%$ para todos os modelos estimados. Já as variáveis $C O M P 1_{i s t}$ e $C O M P_{i s t}$ não tem relação significante com a Lei de Cotas em nenhumas das especificações, quando analisado Minas Gerais. Em São Paulo, o coeficiente de interação entre $C O M P 1_{i s t}, C O M P_{i s t}$ e a Lei de Cotas é negativo e estatisticamente significante para todas as especificações estimadas. Considerando que a proporção de professores com pós graduação em uma escola é indicativo de sua qualidade, observamos que nas "melhores"escolas de São Paulo e Minas Gerais, o impacto da Lei de Cotas é significativamente inferior. 
Tabela 9 - Impacto da Lei de Cotas sobre a escolha de escola - Análise de heterogeniedade

\begin{tabular}{|c|c|c|c|c|c|c|c|c|}
\hline & \multicolumn{4}{|c|}{ Minas Gerais } & \multicolumn{4}{|c|}{ São Paulo } \\
\hline & $(1)$ & $(2)$ & $(3)$ & $(4)$ & $(1)$ & $(2)$ & $(3)$ & $(4)$ \\
\hline \multicolumn{9}{|l|}{ Painel A: Equação 3} \\
\hline Lei de Cotas & $\begin{array}{c}0.101^{* * *} \\
(0.008)\end{array}$ & $\begin{array}{c}0.097^{* * *} \\
(0.008)\end{array}$ & $\begin{array}{c}0.094^{* * *} \\
(0.008)\end{array}$ & $\begin{array}{c}0.094^{* * *} \\
(0.018)\end{array}$ & $\begin{array}{c}0.050^{* * *} \\
(0.003)\end{array}$ & $\begin{array}{c}0.049^{* * *} \\
(0.003)\end{array}$ & $\begin{array}{c}0.048^{* * *} \\
(0.003)\end{array}$ & $\begin{array}{c}0.048^{* * *} \\
(0.009)\end{array}$ \\
\hline Lei de Cotas x POS & $\begin{array}{c}-0.186^{* * *} \\
(0.015)\end{array}$ & $\begin{array}{c}-0.175^{* * *} \\
(0.015)\end{array}$ & $\begin{array}{c}-0.166^{* * *} \\
(0.015)\end{array}$ & $\begin{array}{c}-0.166 * * * \\
(0.036)\end{array}$ & $\begin{array}{c}-0.076^{* * *} \\
(0.007)\end{array}$ & $\begin{array}{c}-0.074^{* * *} \\
(0.007)\end{array}$ & $\begin{array}{c}-0.073^{* * *} \\
(0.007)\end{array}$ & $\begin{array}{c}-0.073^{* * *} \\
(0.021)\end{array}$ \\
\hline Lei de Cotas x COMP & $\begin{array}{c}0.030 \\
(0.042)\end{array}$ & $\begin{array}{c}0.010 \\
(0.042)\end{array}$ & $\begin{array}{l}-0.002 \\
(0.041)\end{array}$ & $\begin{array}{l}-0.002 \\
(0.081)\end{array}$ & $\begin{array}{c}-0.193^{* * *} \\
(0.018)\end{array}$ & $\begin{array}{c}-0.193^{* * *} \\
(0.018)\end{array}$ & $\begin{array}{c}-0.193^{* * *} \\
(0.018)\end{array}$ & $\begin{array}{c}-0.193^{* * *} \\
(0.045)\end{array}$ \\
\hline POS & $\begin{array}{c}0.083^{* * *} \\
(0.007)\end{array}$ & $\begin{array}{c}0.085^{* * *} \\
(0.007)\end{array}$ & $\begin{array}{c}0.086^{* * *} \\
(0.007)\end{array}$ & $\begin{array}{c}0.086^{* * *} \\
(0.019)\end{array}$ & $\begin{array}{c}-0.014^{* * *} \\
(0.003)\end{array}$ & $\begin{array}{c}-0.012^{* * *} \\
(0.003)\end{array}$ & $\begin{array}{c}-0.009^{* * *} \\
(0.003)\end{array}$ & $\begin{array}{l}-0.009 \\
(0.009)\end{array}$ \\
\hline COMP & $\begin{array}{c}-0.130^{* * *} \\
(0.022)\end{array}$ & $\begin{array}{c}-0.106^{* * *} \\
(0.022)\end{array}$ & $\begin{array}{c}-0.080^{* * *} \\
(0.022)\end{array}$ & $\begin{array}{l}-0.080 \\
(0.054)\end{array}$ & $\begin{array}{c}-0.121^{* * *} \\
(0.007)\end{array}$ & $\begin{array}{c}-0.125^{* * *} \\
(0.007)\end{array}$ & $\begin{array}{c}-0.111^{* * *} \\
(0.007)\end{array}$ & $\begin{array}{c}-0.111^{* * *} \\
(0.019)\end{array}$ \\
\hline Obs. & 110691 & 110543 & 110543 & 110543 & 399259 & 399259 & 399259 & 399259 \\
\hline$R^{2}$ & 0.006 & 0.017 & 0.024 & 0.024 & 0.043 & 0.045 & 0.046 & 0.046 \\
\hline \multicolumn{9}{|l|}{ Painel B: Equação 4} \\
\hline Lei de Cotas & $\begin{array}{c}0.037^{* * *} \\
(0.004)\end{array}$ & $\begin{array}{c}0.036^{* * * *} \\
(0.004)\end{array}$ & $\begin{array}{c}0.036^{* * * *} \\
(0.004)\end{array}$ & $\begin{array}{c}0.036^{* * * *} \\
(0.010)\end{array}$ & $\begin{array}{c}0.023^{* * *} \\
(0.002)\end{array}$ & $\begin{array}{c}0.027^{* * *} \\
(0.002)\end{array}$ & $\begin{array}{c}0.026^{* * *} \\
(0.002)\end{array}$ & $\begin{array}{c}0.026^{* * *} \\
(0.006)\end{array}$ \\
\hline Lei de Cotas x POS1 & $\begin{array}{c}-0.059^{* * *} \\
(0.005)\end{array}$ & $\begin{array}{c}-0.057^{* * *} \\
(0.005)\end{array}$ & $\begin{array}{c}-0.055^{* * *} \\
(0.005)\end{array}$ & $\begin{array}{c}-0.055^{* * *} \\
(0.014)\end{array}$ & $\begin{array}{c}-0.024^{* * *} \\
(0.003)\end{array}$ & $\begin{array}{c}-0.023^{* * *} \\
(0.003)\end{array}$ & $\begin{array}{c}-0.023^{* * *} \\
(0.003)\end{array}$ & $\begin{array}{c}-0.023^{* *} \\
(0.009)\end{array}$ \\
\hline Lei de Cotas x COMP1 & $\begin{array}{c}0.001 \\
(0.005)\end{array}$ & $\begin{array}{c}0.001 \\
(0.005)\end{array}$ & $\begin{array}{l}-0.001 \\
(0.005)\end{array}$ & $\begin{array}{l}-0.001 \\
(0.013)\end{array}$ & $\begin{array}{c}-0.037^{* * *} \\
(0.003)\end{array}$ & $\begin{array}{c}-0.036^{* * *} \\
(0.003)\end{array}$ & $\begin{array}{c}-0.036^{* * *} \\
(0.003)\end{array}$ & $\begin{array}{c}-0.036^{* * *} \\
(0.008)\end{array}$ \\
\hline POS1 & $\begin{array}{c}0.028^{* * *} \\
(0.003)\end{array}$ & $\begin{array}{c}0.027^{* * *} \\
(0.003)\end{array}$ & $\begin{array}{c}0.028^{* * *} \\
(0.003)\end{array}$ & $\begin{array}{c}0.028^{* * *} \\
(0.008)\end{array}$ & $\begin{array}{c}-0.003^{* *} \\
(0.001)\end{array}$ & $\begin{array}{c}-0.003^{* *} \\
(0.001)\end{array}$ & $\begin{array}{l}-0.001 \\
(0.001)\end{array}$ & $\begin{array}{l}-0.001 \\
(0.004)\end{array}$ \\
\hline COMP1 & $\begin{array}{c}0.003 \\
(0.002)\end{array}$ & $\begin{array}{l}0.005^{*} \\
(0.002)\end{array}$ & $\begin{array}{c}0.003 \\
(0.002)\end{array}$ & $\begin{array}{c}0.003 \\
(0.006)\end{array}$ & $\begin{array}{c}-0.007^{* * *} \\
(0.001)\end{array}$ & $\begin{array}{c}-0.008^{* * *} \\
(0.001)\end{array}$ & $\begin{array}{c}-0.006^{* * *} \\
(0.001)\end{array}$ & $\begin{array}{l}-0.006 \\
(0.004)\end{array}$ \\
\hline Obs. & 110691 & 110543 & 110543 & 110543 & 399259 & 399259 & 399259 & 399259 \\
\hline$R^{2}$ & 0.005 & 0.016 & 0.023 & 0.023 & 0.042 & 0.044 & 0.046 & 0.046 \\
\hline Variáveis de controle & & SIM & SIM & SIM & & SIM & SIM & SIM \\
\hline Carac. municipais & & & SIM & SIM & & & SIM & SIM \\
\hline Erros clusterizados & & & & SIM & & & & SIM \\
\hline
\end{tabular}

Notas: Em ambos painéis foi utilizado como grupo de controle os alunos de $5^{\circ}$ ano do EF. A significancia estatistica dos resultados e representada por: *** Estatisticamente significante ao nivel de $1 \%,{ }^{* *}$ Estatisticamente significante ao nivel de 5\%, * Estatisticamente significante ao nivel de $10 \%$ 



\section{Robustez}

Como exercício de robutez, realizamos a mesma regressão da especificação (1), sem incluir variáveis de controle e erros clusterizados, para todos os pares de coortes placebo (2009/2010 e 2010/2011) e não placebo (2011/2012, 2012/2013 e 2013/2014), utizando como grupo de controle os alunos de $5^{\circ}$ ano. Observamos que, em Minas Gerais, os coeficientes estimaodos não são significantes à $5 \%$ para todos os períodos placebo e apresentam impacto positivo e signficante para todos os períodos não placebo. Observamos que, em Minas Gerais, o percentual de vagas reservadas se expande progressivamente até 2015 na maior parte das universidades federais, portanto o impacto positivo em períodos posteriores à implementação da Lei é esperado. Já em São Paulo, encontramos nos períodos placebo um pequeno impacto negativo, portanto inverso ao impacto esperado da Lei, que perde a significância quando consideramos nível de significância à 1\%. No períodos posteriores à implementação da Lei, o impacto deixa de ser positivo e significativo, em 2012/2013, e volta a ter sinal negativo no período 2013/2014.
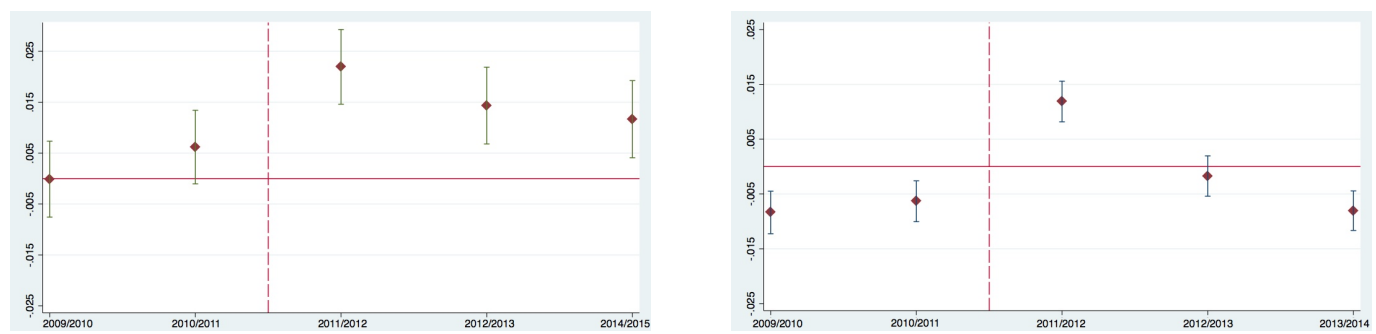

Figura 4 - Coeficiente de interesse estimado para períodos placebo e intervalo de confiança 95\% - Minas Gerais e São Paulo 
Por fim, realizamos as mesmas regressões apresentadas na tabela (7), contudo utilizando como grupo de controle os alunos matriculados na $1^{a}$ série do EM em escola da rede privada. Esses alunos não poderão se beneficiar da Lei de Cotas, já que, ao cursar um dos anos do EM em escola privada, perdem o direito de pleitear uma vaga como cotistas. Os resultados expostos na tabela (10) confirmam o impacto posivo encontrado quando utilizado o primeiro grupo de controle, com execeção da especificação (4), quando analisado apenas duas coortes. Contudo, o ponto estimado é inferior para todas as especificações, indicando um impacto inferior, mas ainda positivo, sobre a escolha de escolha. 
Tabela 10 - Impacto da Lei de Cotas sobre a escolha de escola - Segundo grupo de controle (1 ${ }^{a}$ série do EM)

\begin{tabular}{|c|c|c|c|c|c|c|c|c|}
\hline & \multicolumn{4}{|c|}{$\begin{array}{c}\text { Duas coortes } \\
(2011-2012)\end{array}$} & \multicolumn{4}{|c|}{$\begin{array}{l}\text { Seis coortes } \\
(2009-2014)\end{array}$} \\
\hline & $(1)$ & $(2)$ & $(3)$ & $(4)$ & (1) & $(2)$ & $(3)$ & $(4)$ \\
\hline \multicolumn{9}{|c|}{ Painel A: Minas Gerais } \\
\hline Lei de Cotas & $\begin{array}{c}0.011^{* * *} \\
(0.003)\end{array}$ & $\begin{array}{c}0.011^{* * *} \\
(0.003)\end{array}$ & $\begin{array}{c}0.011^{* * *} \\
(0.003)\end{array}$ & $\begin{array}{c}0.011 \\
(0.007)\end{array}$ & $\begin{array}{c}0.018^{* * *} \\
(0.002)\end{array}$ & $\begin{array}{c}0.017^{* * *} \\
(0.002)\end{array}$ & $\begin{array}{c}0.017^{* * *} \\
(0.002)\end{array}$ & $\begin{array}{c}0.017^{* * *} \\
(0.004)\end{array}$ \\
\hline Obs. & 109421 & 109298 & 109298 & 109298 & 320504 & 320197 & 320197 & 320197 \\
\hline$R^{2}$ & 0.015 & 0.020 & 0.029 & 0.029 & 0.017 & 0.022 & 0.029 & 0.029 \\
\hline \multicolumn{9}{|l|}{ Painel B: São Paulo } \\
\hline Lei de Cotas & $\begin{array}{c}0.007^{* * *} \\
(0.002)\end{array}$ & $\begin{array}{c}0.007^{* * *} \\
(0.002)\end{array}$ & $\begin{array}{c}0.007^{* * *} \\
(0.002)\end{array}$ & $\begin{array}{c}0.007 \\
(0.005)\end{array}$ & $\begin{array}{c}-0.009^{* * *} \\
(0.001)\end{array}$ & $\begin{array}{c}-0.010^{* * *} \\
(0.001)\end{array}$ & $\begin{array}{c}-0.010^{* * *} \\
(0.001)\end{array}$ & $\begin{array}{c}-0.010^{* *} \\
(0.003)\end{array}$ \\
\hline Obs. & 375283 & 375283 & 375283 & 375283 & 1111647 & 1045640 & 1045640 & 1045640 \\
\hline$R^{2}$ & 0.031 & 0.032 & 0.034 & 0.034 & 0.031 & 0.032 & 0.035 & 0.035 \\
\hline Variáveis de controle & & SIM & SIM & SIM & & SIM & SIM & SIM \\
\hline Carac. municipais & & & SIM & SIM & & & SIM & SIM \\
\hline Erros clusterizados & & & & SIM & & & & SIM \\
\hline
\end{tabular}

Notas: A tabela esta dividida em dois painéis. No painel A sao apresentadas estimativas para o estado de

Minas Gerais. No painel B são apresentadas as estimativas para o estado de São Paulo. Em ambos painéis foi utilizado como grupo de controle os alunos da $1^{\text {a }}$ série do EM. A significancia estatistica dos resultados e representada por: ${ }^{* * *}$ Estatisticamente significante ao nivel de $1 \%,{ }^{* *}$ Estatisticamente significante ao nivel de $5 \%, *$ Estatisticamente significante ao nivel de $10 \%$ 



\section{Conclusão}

Ao instituir que $50 \%$ das vagas em todas as universidades federais do país devem ser destinadas para alunos que estudaram o ensino médio integralmente em escolas públicas, a Lei de Cotas cria um incentivo para que alunos matriculados no último ano do EF em escolas privadas migrem para a rede pública no primeiro ano do EM. Esse incetivo é maior em estados onde as universidades federais representam uma maior parcela mais signifititiva do sistema púbico de ensino superior e onde a Lei representa uma mudança instucional em relação às ações afirmativas adotadas anteriormente à 2013.

A partir de uma regressão de Diferenças-em-Diferenças, observamos que em Minas Gerais, estado com a maior parcela de alunos de universidades públicas matriculados em instituições federaias e onde a Lei representa uma mudança institucional significativa no acesso ao ensino superior público, a probabilidade de migração para rede pública dos alunos matriculados no último ano do ensino fundamental aumenta em cerca de 2,2 p.p, um aumento de $20 \%$ em relação ao período anterior à Lei. Já em São Paulo, onde a Lei não acarreta em mudanças no mesmo grau, já que as universidades estaduais, que não são afetadas pela Lei de Cotas, representam a maior parcelo do sistema público, o aumento estimado é de apenas $8 \%$.

Observamos ainda que, em Minas Gerais e São Paulo, os alunos provenientes de escolas particulares de maior qualidade, mensurado como o percentual de professores que possuem pós graduação na escola desse aluno, são menos impactados pela Lei, indicando que o impacto da Lei está focalizado nos alunos provenientes das piores escolas de cada localidade.

Os resultados encontrados nesta dissertação vão de encontro à literatura que analisa o impacto de ações afirmativas do tipo color-blind sobre a escolha de escolas, como Estevan et al. (2012) e Cullen, Long e Reback (2013). A implementação de AA que beneficiam um grupo específico de escolas no acesso ao ensino superior, podem levar a um comportamento estratégico na escolha de escola por parte dos alunos matriculados no ensino básico. 



\section{Referências}

CULlEN, J. B.; LONG, M. C.; REBACK, R. Jockeying for position: Strategic high school choice under texas' top ten percent plan. Journal of Public Economics, Elsevier, v. 97 , p. $32-48,2013.21,34,59$

EMILIO, D. R.; JR, W. B.; ALVES, D. Uma análise econometrica dos determinantes do acesso à universidade de são paulo. Pesquisa Planejamento Econômico, v. 34, n. 2, 2004. 24

EPPLE, D.; FIGLIO, D.; ROMANO, R. Competition between private and public schools: testing stratification and pricing predictions. Journal of public Economics, Elsevier, v. 88, n. 7 , p. $1215-1245,2004.36$

EPPLE, D.; ROMANO, R. E. Competition between private and public schools, vouchers, and peer-group effects. American Economic Review, JSTOR, p. 33-62, 1998. 35

ESTEVAN, F. The quality of public education and private school enrollment: an assessment using Brazilian data. [S.1.]: Boston university. Institute for economic development (IED), 2009. 36

ESTEVAN, F. Public Education Expenditures and Private School Enrollment. [S.1.], 2014. 36,38

ESTEVAN, F. et al. College admission and high school integration. [S.1.], 2012. 21, 33, 59

FERMAN, B.; ASSUNCAO, J. Affirmative action in university admissions and high school students' proficiency. [S.1.], 2005. 34

FRANCIS, A. M.; TANNURI-PIANTO, M. Using brazil's racial continuum to examine the short-term effects of affirmative action in higher education. Journal of Human Resources, University of Wisconsin Press, v. 47, n. 3, p. 754-784, 2012. 34

FRYER, R.; LOURY, G. C.; YURET, T. Color-blind affirmative action. [S.1.], 2003. 33, 34

JUNIOR, J. F. et al. O impacto da lei n 12.711 sobre as universidades federais.

Levantamento das politicas de ação afirmativa, p. 1-34, 2013. 28

LONG, J. E.; TOMA, E. F. The determinants of private school attendance, 1970-1980. The Review of Economics and Statistics, JSTOR, p. 351-357, 1988. 35

MENEZES-FILHO, N.; MOITA, R.; ANDRADE, E. de C. Running away from the poor: Bolsa-familia and entry in school markets. CEP, v. 4546, p. 042, 2014. 36

MENEZES-FILHO, N. A.; CURI, A. Z. et al. Os determinantes dos gastos com educação no brasil. In: Anais do XXXVII Encontro Nacional de Economia [Proceedings of the 37th Brazilian Economics Meeting]. [S.l.: s.n.], 2011. 35

OPICE, I. B. Determinantes da escolha entre o setor público e privado e alocação dos alunos nas escolas. Dissertação (Mestrado) - Universidade de São Paulo, 2015. 35 

Apêndice 
Tabela A1 - Impacto da Lei de Cotas sobre a escolha de escola

\begin{tabular}{|c|c|c|c|c|c|c|c|c|}
\hline & \multicolumn{4}{|c|}{ Minas Gerais } & \multicolumn{4}{|c|}{ São Paulo } \\
\hline & (1) & $(2)$ & $(3)$ & $(4)$ & $(1)$ & $(2)$ & $(3)$ & $(4)$ \\
\hline \multicolumn{9}{|c|}{ Painel A: Duas coortes (2011 e 2012) } \\
\hline \multirow[t]{2}{*}{ ano } & $0.00499^{* *}$ & $0.00689^{* * *}$ & 0.00949 & 0.00949 & 0.00145 & $0.00338^{* * *}$ & $0.00345^{* * *}$ & 0.00345 \\
\hline & $(0.00249)$ & $(0.00258)$ & $(0.00662)$ & $(0.00662)$ & $(0.000915)$ & $(0.000928)$ & $(0.000939)$ & $(0.00229)$ \\
\hline \multirow[t]{2}{*}{ trat } & $0.0162^{* * *}$ & $0.0181^{* * *}$ & $0.0181^{* * *}$ & $0.0181^{* * *}$ & $0.117^{* * *}$ & $0.118^{* * *}$ & $0.117^{* * *}$ & $0.117^{* * *}$ \\
\hline & $(0.00256)$ & $(0.00255)$ & $(0.00583)$ & $(0.00583)$ & $(0.00133)$ & $(0.00132)$ & $(0.00132)$ & $(0.00374)$ \\
\hline \multirow[t]{2}{*}{ Lei de Cotas } & $0.0219^{* * *}$ & $0.0216^{* * *}$ & $0.0218^{* * *}$ & $0.0218^{* * *}$ & $0.0119^{* * *}$ & $0.0117^{* * *}$ & $0.0117^{* * *}$ & $0.0117^{* *}$ \\
\hline & $(0.00374)$ & $(0.00372)$ & $(0.00841)$ & $(0.00841)$ & $(0.00189)$ & $(0.00189)$ & $(0.00189)$ & $(0.00516)$ \\
\hline \multirow[t]{2}{*}{ IDEB } & & $-0.00447^{*}$ & $-0.0151^{*}$ & $-0.0151^{*}$ & & $-0.0215^{* * *}$ & $-0.0213^{* * *}$ & $-0.0213^{* * *}$ \\
\hline & & $(0.00271)$ & $(0.00881)$ & $(0.00881)$ & & $(0.00156)$ & $(0.00218)$ & $(0.00643)$ \\
\hline \multirow[t]{2}{*}{ OR } & & $-0.0713^{* * *}$ & $-0.0428^{* * *}$ & $-0.0428^{* * *}$ & & $-0.0356^{* * *}$ & $-0.0186^{* * *}$ & $-0.0186^{* * *}$ \\
\hline & & $(0.00213)$ & $(0.00578)$ & $(0.00578)$ & & $(0.00129)$ & $(0.00152)$ & $(0.00426)$ \\
\hline \multirow[t]{2}{*}{ Desigualdade de Renda } & & & $-0.504^{* * *}$ & $-0.504^{* * *}$ & & & $-0.396 * * *$ & $-0.396^{* * *}$ \\
\hline & & & $(0.131)$ & $(0.131)$ & & & $(0.0243)$ & $(0.0651)$ \\
\hline \multirow[t]{2}{*}{ Pobreza } & & & $0.00469^{* * *}$ & $0.00469^{* * *}$ & & & $0.00555^{* * *}$ & $0.00555^{* * *}$ \\
\hline & & & $(0.00122)$ & $(0.00122)$ & & & $(0.000519)$ & $(0.00135)$ \\
\hline \multirow[t]{2}{*}{ Renda per capita } & & & $6.71 \mathrm{e}-05^{*}$ & $6.71 \mathrm{e}-05^{*}$ & & & $6.91 \mathrm{e}-06$ & $6.91 \mathrm{e}-06$ \\
\hline & & & $(3.66 \mathrm{e}-05)$ & $(3.66 \mathrm{e}-05)$ & & & $(5.01 \mathrm{e}-06)$ & $(1.37 \mathrm{e}-05)$ \\
\hline \multirow[t]{2}{*}{ População } & & & 0 & 0 & & & $0^{* * *}$ & $0^{* * *}$ \\
\hline & & & $(5.66 \mathrm{e}-11)$ & $(5.66 \mathrm{e}-11)$ & & & 0 & 0 \\
\hline \multirow[t]{2}{*}{ IDHM Educação } & & & $-0.222^{* *}$ & $-0.222^{* *}$ & & & $0.142^{* * *}$ & $0.142^{* *}$ \\
\hline & & & $(0.0865)$ & $(0.0865)$ & & & $(0.0225)$ & $(0.0602)$ \\
\hline \multirow[t]{2}{*}{ Constante } & $0.0929^{* * *}$ & $0.181^{* * *}$ & $0.523^{* * *}$ & $0.523^{* * *}$ & $0.0424^{* * *}$ & $0.170^{* * * *}$ & $0.220^{* * *}$ & $0.220^{* * *}$ \\
\hline & $(0.00173)$ & $(0.0116)$ & $(0.0784)$ & $(0.0784)$ & $(0.000647)$ & $(0.00703)$ & $(0.0203)$ & $(0.0558)$ \\
\hline Obs. & 110,691 & 110,543 & 110,543 & 110,543 & 399,259 & 399,259 & 399,259 & 399,259 \\
\hline$R^{2}$ & 0.003 & 0.014 & 0.022 & 0.022 & 0.040 & 0.042 & 0.044 & 0.044 \\
\hline \multicolumn{9}{|c|}{ Painel B: Seis coortes (2009 - 2014) } \\
\hline \multirow[t]{2}{*}{ ano } & $-0.00626^{* * *}$ & $-0.00503^{* * *}$ & -0.000446 & -0.000446 & $-0.00152^{* * *}$ & 0.000756 & $0.00167^{* * *}$ & 0.00167 \\
\hline & $(0.00144)$ & $(0.00158)$ & $(0.00165)$ & $(0.00411)$ & $(0.000526)$ & $(0.000576)$ & $(0.000588)$ & $(0.00148)$ \\
\hline \multirow[t]{2}{*}{ trat } & $0.0121^{* * *}$ & $0.0144^{* * *}$ & $0.0143^{* * *}$ & $0.0143^{* * *}$ & $0.124^{* * *}$ & $0.125^{* * *}$ & $0.124^{* * *}$ & $0.124^{* * *}$ \\
\hline & $(0.00153)$ & $(0.00152)$ & $(0.00152)$ & $(0.00348)$ & $(0.000793)$ & $(0.000793)$ & $(0.000792)$ & $(0.00244)$ \\
\hline Lei de Cotas & $0.0395^{* * *}$ & $0.0391^{* * *}$ & $0.0389^{* * *}$ & $0.0389^{* * *}$ & 0.00127 & 0.000755 & 0.000727 & 0.000727 \\
\hline & $(0.00220)$ & $(0.00218)$ & $(0.00218)$ & $(0.00499)$ & $(0.00110)$ & $(0.00113)$ & $(0.00113)$ & $(0.00318)$ \\
\hline IDEB & & $-0.0140^{* * *}$ & $-0.0201^{* * *}$ & $-0.0201^{* * *}$ & & $-0.0238^{* * *}$ & $-0.0254^{* * *}$ & $-0.0254^{* * *}$ \\
\hline & & $(0.00150)$ & $(0.00188)$ & $(0.00466)$ & & $(0.000885)$ & $(0.00120)$ & $(0.00364)$ \\
\hline OR & & $-0.0713^{* * *}$ & $-0.0449^{* * *}$ & $-0.0449^{* * *}$ & & $-0.0349^{* * *}$ & $-0.0171^{* * *}$ & $-0.0171^{* * *}$ \\
\hline & & $(0.00126)$ & $(0.00150)$ & $(0.00357)$ & & $(0.000721)$ & $(0.000845)$ & $(0.00246)$ \\
\hline Desigualdade de Renda & & & $-0.535^{* * *}$ & $-0.535^{* * *}$ & & & $-0.398^{* * *}$ & $-0.398^{* * *}$ \\
\hline & & & $(0.0308)$ & $(0.0758)$ & & & $(0.0139)$ & $(0.0383)$ \\
\hline Pobreza & & & $0.00492^{* * *}$ & $0.00492^{* * *}$ & & & $0.00502^{* * *}$ & $0.00502^{* * * *}$ \\
\hline & & & $(0.000322)$ & $(0.000730)$ & & & $(0.000294)$ & $(0.000795)$ \\
\hline Renda per capita & & & $6.69 \mathrm{e}-05^{* * *}$ & $6.69 \mathrm{e}-05^{* * *}$ & & & $3.15 \mathrm{e}-06$ & $3.15 \mathrm{e}-06$ \\
\hline & & & $(8.31 \mathrm{e}-06)$ & $(2.13 \mathrm{e}-05)$ & & & $(2.86 \mathrm{e}-06)$ & $(7.95 \mathrm{e}-06)$ \\
\hline População & & & 0 & 0 & & & $0^{* * *}$ & $0^{* * *}$ \\
\hline & & & 0 & 0 & & & 0 & 0 \\
\hline IDHM Educação & & & $-0.189^{* * *}$ & $-0.189^{* * *}$ & & & $0.111^{* * *}$ & $0.111^{* * *}$ \\
\hline & & & $(0.0179)$ & $(0.0497)$ & & & $(0.0130)$ & $(0.0352)$ \\
\hline Constante & $0.1000^{* * *}$ & $0.225^{* * *}$ & $0.541^{* * * *}$ & $0.541^{* * *}$ & $0.0441^{* * *}$ & $0.180^{* * *}$ & $0.267^{* * *}$ & $0.267^{* * *}$ \\
\hline & $(0.00105)$ & $(0.00639)$ & $(0.0167)$ & $(0.0454)$ & $(0.000379)$ & $(0.00393)$ & $(0.0116)$ & $(0.0319)$ \\
\hline Obs. & 331,278 & 330,955 & 330,955 & 330,955 & $1,201,679$ & $1,126,743$ & $1,126,743$ & $1,126,743$ \\
\hline$R^{2}$ & 0.004 & 0.015 & 0.022 & 0.022 & 0.041 & 0.043 & 0.045 & 0.045 \\
\hline Variáveis de controle & & SIM & SIM & SIM & & SIM & SIM & SIM \\
\hline Carac. municipais & & & SIM & SIM & & & SIM & SIM \\
\hline Erros clusterizados & & & & SIM & & & & SIM \\
\hline
\end{tabular}

Notas: A significancia estatistica dos resultados e representada por: *** Estatisticamente significante ao nivel de 1\%, ** Estatisticamente significante ao nivel de 5\%, * Estatisticamente significante ao nivel de $10 \%$ 
Tabela A2 - Impacto da Lei de Cotas sobre a escolha de escola - Alunos que estudaram os últimos 3 anos em escolas privadas



Notas: A significancia estatistica dos resultados e representada por: ${ }^{* * *}$ Estatisticamente significante ao nivel de 1\%, ** Estatisticamente significante ao nivel de 5\%, * Estatisticamente significante ao nivel de $10 \%$ 
Tabela A3 - Impacto da Lei de Cotas sobre a escolha de escola - Analise de heterogeniedaed - Equação4

\begin{tabular}{|c|c|c|c|c|c|c|c|c|}
\hline & \multicolumn{4}{|c|}{ Minas Gerais } & \multicolumn{4}{|c|}{ São Paulo } \\
\hline & $(1)$ & $(2)$ & $(3)$ & (4) & $(1)$ & $(2)$ & $(3)$ & $(4)$ \\
\hline ano & $\begin{array}{c}0.00761^{* * *} \\
(0.00247)\end{array}$ & $\begin{array}{c}0.00971^{* * *} \\
(0.00257)\end{array}$ & $\begin{array}{c}0.0124^{* * *} \\
(0.00264)\end{array}$ & $\begin{array}{c}0.0124^{*} \\
(0.00666)\end{array}$ & $\begin{array}{c}0.00107 \\
(0.000915)\end{array}$ & $\begin{array}{c}0.00303^{* * *} \\
(0.000928)\end{array}$ & $\begin{array}{c}0.00308^{* * *} \\
(0.000939)\end{array}$ & $\begin{array}{c}0.00308 \\
(0.00230)\end{array}$ \\
\hline trat & $\begin{array}{c}0.0180^{* * *} \\
(0.00255)\end{array}$ & $\begin{array}{c}0.0199^{* * *} \\
(0.00254)\end{array}$ & $\begin{array}{c}0.0198^{* * *} \\
(0.00253)\end{array}$ & $\begin{array}{c}0.0198^{* * *} \\
(0.00578)\end{array}$ & $\begin{array}{l}0.117^{* * *} \\
(0.00132)\end{array}$ & $\begin{array}{l}0.118^{* * *} \\
(0.00132)\end{array}$ & $\begin{array}{l}0.118^{* * *} \\
(0.00132)\end{array}$ & $\begin{array}{l}0.118^{* * *} \\
(0.00374)\end{array}$ \\
\hline Lei de Cotas & $\begin{array}{l}0.101 * * * \\
(0.00774)\end{array}$ & $\begin{array}{c}0.0973^{* * *} \\
(0.00766)\end{array}$ & $\begin{array}{c}0.0939^{* * *} \\
(0.00761)\end{array}$ & $\begin{array}{c}0.0939^{* * *} \\
(0.0183)\end{array}$ & $\begin{array}{c}0.0497 * * * \\
(0.00331)\end{array}$ & $\begin{array}{c}0.0487^{* * *} \\
(0.00331)\end{array}$ & $\begin{array}{c}0.0484^{* * *} \\
(0.00331)\end{array}$ & $\begin{array}{c}0.0484^{* * *} \\
(0.00890)\end{array}$ \\
\hline IDEB & & $\begin{array}{c}-0.00501^{*} \\
(0.00271)\end{array}$ & $\begin{array}{c}-0.0158^{* * *} \\
(0.00369)\end{array}$ & $\begin{array}{l}-0.0158^{*} \\
(0.00886)\end{array}$ & & $\begin{array}{c}-0.0214^{* * *} \\
(0.00156)\end{array}$ & $\begin{array}{c}-0.0203^{* * *} \\
(0.00218)\end{array}$ & $\begin{array}{c}-0.0203^{* * *} \\
(0.00643)\end{array}$ \\
\hline OR & & $\begin{array}{c}-0.0708^{* * *} \\
(0.00212)\end{array}$ & $\begin{array}{c}-0.0426^{* * *} \\
(0.00267)\end{array}$ & $\begin{array}{c}-0.0426^{* * *} \\
(0.00586)\end{array}$ & & $\begin{array}{c}-0.0354^{* * *} \\
(0.00129)\end{array}$ & $\begin{array}{c}-0.0207^{* * *} \\
(0.00152)\end{array}$ & $\begin{array}{c}-0.0207^{* * * *} \\
(0.00422)\end{array}$ \\
\hline Desigualdade de Renda & & & $-0.525^{* * *}$ & $-0.525^{* * *}$ & & & $-0.384^{* * *}$ & $-0.384^{* * *}$ \\
\hline Pobreza & & & $\begin{array}{c}0.00471^{* * *} \\
(0.000553)\end{array}$ & $\begin{array}{c}0.00471^{* * *} \\
(0.00123)\end{array}$ & & & $\begin{array}{c}0.00538^{* * *} \\
(0.000518)\end{array}$ & $\begin{array}{c}0.00538^{* * *} \\
(0.00135)\end{array}$ \\
\hline Renda per capita & & & $\begin{array}{c}6.71 \mathrm{e}-05^{* * *} \\
(1.46 \mathrm{e}-05)\end{array}$ & $\begin{array}{l}6.71 \mathrm{e}-05^{*} \\
(3.67 \mathrm{e}-05)\end{array}$ & & & $\begin{array}{l}1.09 \mathrm{e}-05^{* *} \\
(5.01 \mathrm{e}-06)\end{array}$ & $\begin{array}{c}1.09 \mathrm{e}-05 \\
(1.38 \mathrm{e}-05)\end{array}$ \\
\hline População & & & $\begin{array}{l}-0 \\
(0)\end{array}$ & $\begin{array}{c}-0 \\
(5.73 \mathrm{e}-11)\end{array}$ & & & $\begin{array}{l}0^{* * *} \\
(0)\end{array}$ & $\begin{array}{c}0^{* * *} \\
(0)\end{array}$ \\
\hline IDHM Educação & & & $\begin{array}{c}-0.214^{* * *} \\
(0.0316)\end{array}$ & $\begin{array}{c}-0.214^{* *} \\
(0.0863)\end{array}$ & & & $\begin{array}{c}0.132 * * * \\
(0.0225)\end{array}$ & $\begin{array}{l}0.132^{* *} \\
(0.0601)\end{array}$ \\
\hline Lei de Cotas x POS & $\begin{array}{c}-0.186^{* * *} \\
(0.0146)\end{array}$ & $\begin{array}{c}-0.175^{* * *} \\
(0.0145)\end{array}$ & $\begin{array}{c}-0.166^{* * *} \\
(0.0144)\end{array}$ & $\begin{array}{c}-0.166^{* * *} \\
(0.0364)\end{array}$ & $\begin{array}{c}-0.0757^{* * *} \\
(0.00687)\end{array}$ & $\begin{array}{c}-0.0736^{* * *} \\
(0.00686)\end{array}$ & $\begin{array}{c}-0.0728^{* * *} \\
(0.00686)\end{array}$ & $\begin{array}{c}-0.0728^{* * *} \\
(0.0214)\end{array}$ \\
\hline Lei de Cotas x COMP & $\begin{array}{c}0.0299 \\
(0.0420)\end{array}$ & $\begin{array}{l}0.0104 \\
(0.0416)\end{array}$ & $\begin{array}{l}-0.00237 \\
(0.0414)\end{array}$ & $\begin{array}{l}-0.00237 \\
(0.0811)\end{array}$ & $\begin{array}{c}-0.193^{* * *} \\
(0.0177)\end{array}$ & $\begin{array}{c}-0.193^{* * *} \\
(0.0177)\end{array}$ & $\begin{array}{c}-0.193^{* * *} \\
(0.0176)\end{array}$ & $\begin{array}{c}-0.193^{* * *} \\
(0.0450)\end{array}$ \\
\hline POS & $\begin{array}{c}0.0831 * * * \\
(0.00692)\end{array}$ & $\begin{array}{c}0.0851^{* * *} \\
(0.00690)\end{array}$ & $\begin{array}{l}0.0857 * * * \\
(0.00699)\end{array}$ & $\begin{array}{c}0.0857 * * * \\
(0.0187)\end{array}$ & $\begin{array}{c}-0.0138^{* * *} \\
(0.00264)\end{array}$ & $\begin{array}{c}-0.0124^{* * *} \\
(0.00264)\end{array}$ & $\begin{array}{c}-0.00935 * * * \\
(0.00264)\end{array}$ & $\begin{array}{l}-0.00935 \\
(0.00873)\end{array}$ \\
\hline COMP & $\begin{array}{c}-0.130 * * * \\
(0.0219)\end{array}$ & $\begin{array}{c}-0.106^{* * *} \\
(0.0217)\end{array}$ & $\begin{array}{c}-0.0805^{* * *} \\
(0.0216)\end{array}$ & $\begin{array}{l}-0.0805 \\
(0.0536)\end{array}$ & $\begin{array}{c}-0.121^{* * *} \\
(0.00711)\end{array}$ & $\begin{array}{l}-0.125^{* * *} \\
(0.00713)\end{array}$ & $\begin{array}{l}-0.111^{* * *} \\
(0.00715)\end{array}$ & $\begin{array}{c}-0.111^{* * *} \\
(0.0192)\end{array}$ \\
\hline $\begin{array}{l}\text { Constante } \\
0.225^{* * *}\end{array}$ & $0.0581^{* * *}$ & $0.146^{* * *}$ & $0.492^{* * *}$ & $0.492 * * *$ & $0.0545^{* * *}$ & $(0.00710)$ & $0.181^{* * *}$ & $0.225^{* * *}$ \\
\hline $\begin{array}{l}\text { Obs. } \\
R^{2}\end{array}$ & $\begin{array}{c}110,691 \\
0.006\end{array}$ & $\begin{array}{c}110,543 \\
0.017\end{array}$ & $\begin{array}{c}110,543 \\
0.024\end{array}$ & $\begin{array}{c}110,543 \\
0.024\end{array}$ & $\begin{array}{c}399,259 \\
0.043\end{array}$ & $\begin{array}{c}399,259 \\
0.045\end{array}$ & $\begin{array}{c}399,259 \\
0.046\end{array}$ & $\begin{array}{c}399,259 \\
0.046\end{array}$ \\
\hline $\begin{array}{l}\text { Variáveis de controle } \\
\text { Carac. municipais } \\
\text { Erros clusterizados }\end{array}$ & & SIM & $\begin{array}{l}\text { SIM } \\
\text { SIM }\end{array}$ & $\begin{array}{l}\text { SIM } \\
\text { SIM } \\
\text { SIM }\end{array}$ & & SIM & $\begin{array}{l}\text { SIM } \\
\text { SIM }\end{array}$ & $\begin{array}{l}\text { SIM } \\
\text { SIM } \\
\text { SIM }\end{array}$ \\
\hline
\end{tabular}

Notas: A significancia estatistica dos resultados e representada por: *** Estatisticamente significante ao nivel de 1\%, ** Estatisticamente significante ao nivel de 5\%, * Estatisticamente significante ao nivel de $10 \%$ 
Tabela A4 - Impacto da Lei de Cotas sobre a escolha de escola - Analise de heterogeniedaded - Equação 4

\begin{tabular}{|c|c|c|c|c|c|c|c|c|}
\hline & \multicolumn{4}{|c|}{ Minas Gerais } & \multicolumn{4}{|c|}{ São Paulo } \\
\hline & (1) & $(2)$ & (3) & (4) & (1) & $(2)$ & $(3)$ & (4) \\
\hline ano & $\begin{array}{c}0.00498^{* *} \\
(0.00248)\end{array}$ & $\begin{array}{c}0.00740^{* * *} \\
(0.00257)\end{array}$ & $\begin{array}{c}0.00992 \\
(0.00666)\end{array}$ & $\begin{array}{c}0.00992 \\
(0.00666)\end{array}$ & $\begin{array}{c}0.00145 \\
(0.000915)\end{array}$ & $\begin{array}{c}0.00344^{* * *} \\
(0.000928)\end{array}$ & $\begin{array}{c}0.00339 * * * \\
(0.000939)\end{array}$ & $\begin{array}{c}0.00339 \\
(0.00229)\end{array}$ \\
\hline trat & $\begin{array}{c}0.0162^{* * *} \\
(0.00256)\end{array}$ & $\begin{array}{c}0.0182^{* * *} \\
(0.00255)\end{array}$ & $\begin{array}{c}0.0181^{* * *} \\
(0.00578)\end{array}$ & $\begin{array}{c}0.0181^{* * *} \\
(0.00578)\end{array}$ & $\begin{array}{l}0.117^{* * *} \\
(0.00133)\end{array}$ & $\begin{array}{c}0.118^{* * *} \\
(0.00132)\end{array}$ & $\begin{array}{l}0.118^{* * *} \\
(0.00132)\end{array}$ & $\begin{array}{l}0.118^{* * *} \\
(0.00373)\end{array}$ \\
\hline Lei de Cotas & $\begin{array}{c}0.0366^{* * *} \\
(0.00424)\end{array}$ & $\begin{array}{c}0.0358^{* * *} \\
(0.00421)\end{array}$ & $\begin{array}{c}0.0358^{* * *} \\
(0.00978)\end{array}$ & $\begin{array}{c}0.0358^{* * *} \\
(0.00978)\end{array}$ & $\begin{array}{c}0.0268^{* * *} \\
(0.00219)\end{array}$ & $\begin{array}{c}0.0265^{* * *} \\
(0.00218)\end{array}$ & $\begin{array}{c}0.0265^{* * *} \\
(0.00218)\end{array}$ & $\begin{array}{c}0.0265^{* * *} \\
(0.00573)\end{array}$ \\
\hline IDEB & & $\begin{array}{c}-0.00632^{* *} \\
(0.00273)\end{array}$ & $\begin{array}{l}-0.0166^{*} \\
(0.00885)\end{array}$ & $\begin{array}{l}-0.0166^{*} \\
(0.00885)\end{array}$ & & $\begin{array}{c}-0.0221^{* * *} \\
(0.00156)\end{array}$ & $\begin{array}{c}-0.0207^{* * *} \\
(0.00218)\end{array}$ & $\begin{array}{c}-0.0207^{* * *} \\
(0.00645)\end{array}$ \\
\hline OR & & $\begin{array}{c}-0.0710^{* * *} \\
(0.00212)\end{array}$ & $\begin{array}{c}-0.0424^{* * *} \\
(0.00583)\end{array}$ & $\begin{array}{c}-0.0424^{* * *} \\
(0.00583)\end{array}$ & & $\begin{array}{c}-0.0357^{* * *} \\
(0.00129)\end{array}$ & $\begin{array}{c}-0.0197 * * * \\
(0.00152)\end{array}$ & $\begin{array}{c}-0.0197^{* * *} \\
(0.00424)\end{array}$ \\
\hline Desigualdade de Renda & & & $\begin{array}{c}-0.514^{* * * *} \\
(0.131)\end{array}$ & $\begin{array}{c}-0.514^{* * *} \\
(0.131)\end{array}$ & & & $\begin{array}{c}-0.385^{* * *} \\
(0.0243)\end{array}$ & $\begin{array}{c}-0.385^{* * *} \\
(0.0647)\end{array}$ \\
\hline Pobreza & & & $\begin{array}{c}0.00477^{* * *} \\
(0.00122)\end{array}$ & $\begin{array}{c}0.00477^{* * *} \\
(0.00122)\end{array}$ & & & $\begin{array}{c}0.00554^{* * *} \\
(0.000519)\end{array}$ & $\begin{array}{c}0.00554^{* * *} \\
(0.00135)\end{array}$ \\
\hline Renda per capita & & & $\begin{array}{c}6.83 \mathrm{e}-05^{*} \\
(3.66 \mathrm{e}-05)\end{array}$ & $\begin{array}{c}6.83 \mathrm{e}-05^{*} \\
(3.66 \mathrm{e}-05)\end{array}$ & & & $\begin{array}{l}9.26 \mathrm{e}-06^{*} \\
(5.01 \mathrm{e}-06)\end{array}$ & $\begin{array}{c}9.26 \mathrm{e}-06 \\
(1.37 \mathrm{e}-05)\end{array}$ \\
\hline População & & & $\begin{array}{c}0 \\
(5.74 \mathrm{e}-11)\end{array}$ & $\begin{array}{c}0 \\
(5.74 \mathrm{e}-11)\end{array}$ & & & $\begin{array}{c}0^{* * *} \\
0\end{array}$ & $\begin{array}{c}0^{* * *} \\
0\end{array}$ \\
\hline IDHM Educação & & & $\begin{array}{c}-0.220^{* *} \\
(0.0861)\end{array}$ & $\begin{array}{c}-0.220^{* *} \\
(0.0861)\end{array}$ & & & $\begin{array}{c}0.128^{* * *} \\
(0.0225)\end{array}$ & $\begin{array}{l}0.128^{* *} \\
(0.0603)\end{array}$ \\
\hline Lei de Cotas x POS1 & $\begin{array}{c}-0.0591^{* * *} \\
(0.00518)\end{array}$ & $\begin{array}{c}-0.0568^{* * *} \\
(0.00518)\end{array}$ & $\begin{array}{c}-0.0552^{* * *} \\
(0.0139)\end{array}$ & $\begin{array}{c}-0.0552^{* * *} \\
(0.0139)\end{array}$ & $\begin{array}{c}-0.0239^{* * *} \\
(0.00288)\end{array}$ & $\begin{array}{c}-0.0230^{* * *} \\
(0.00288)\end{array}$ & $\begin{array}{c}-0.0227^{* * *} \\
(0.00288)\end{array}$ & $\begin{array}{c}-0.0227^{* *} \\
(0.00902)\end{array}$ \\
\hline Lei de Cotas x COMP1 & $\begin{array}{l}0.000562 \\
(0.00536)\end{array}$ & $\begin{array}{l}0.000130 \\
(0.00533)\end{array}$ & $\begin{array}{c}-0.00104 \\
(0.0134)\end{array}$ & $\begin{array}{c}-0.00104 \\
(0.0134)\end{array}$ & $\begin{array}{c}-0.0357^{* * *} \\
(0.00283)\end{array}$ & $\begin{array}{c}-0.0361^{* * *} \\
(0.00283)\end{array}$ & $\begin{array}{c}-0.0364^{* * *} \\
(0.00282)\end{array}$ & $\begin{array}{c}-0.0364^{* * *} \\
(0.00833)\end{array}$ \\
\hline POS1 & $\begin{array}{c}0.0276^{* * *} \\
(0.00254)\end{array}$ & $\begin{array}{c}0.0271^{* * *} \\
(0.00255)\end{array}$ & $\begin{array}{c}0.0283^{* * *} \\
(0.00797)\end{array}$ & $\begin{array}{c}0.0283^{* * *} \\
(0.00797)\end{array}$ & $\begin{array}{c}-0.00281^{* *} \\
(0.00114)\end{array}$ & $\begin{array}{c}-0.00261^{* *} \\
(0.00114)\end{array}$ & $\begin{array}{l}-0.00135 \\
(0.00114)\end{array}$ & $\begin{array}{l}-0.00135 \\
(0.00389)\end{array}$ \\
\hline COMP1 & $\begin{array}{c}0.00262 \\
(0.00242)\end{array}$ & $\begin{array}{l}0.00468^{*} \\
(0.00241)\end{array}$ & $\begin{array}{c}0.00261 \\
(0.00641)\end{array}$ & $\begin{array}{c}0.00261 \\
(0.00641)\end{array}$ & $\begin{array}{c}-0.00711^{* * *} \\
(0.00113)\end{array}$ & $\begin{array}{c}-0.00766^{* * *} \\
(0.00113)\end{array}$ & $\begin{array}{c}-0.00576^{* * *} \\
(0.00113)\end{array}$ & $\begin{array}{l}-0.00576 \\
(0.00364)\end{array}$ \\
\hline Constante & $\begin{array}{c}0.0853^{* * *} \\
(0.00185)\end{array}$ & $\begin{array}{c}0.180^{* * *} \\
(0.0116)\end{array}$ & $\begin{array}{c}0.523^{* * *} \\
(0.0781)\end{array}$ & $\begin{array}{c}0.523^{* * *} \\
(0.0781)\end{array}$ & $\begin{array}{l}0.0449 * * * \\
(0.000733)\end{array}$ & $\begin{array}{l}0.175^{* * *} \\
(0.00707)\end{array}$ & $\begin{array}{c}0.223^{* * *} \\
(0.0203)\end{array}$ & $\begin{array}{c}0.223^{* * *} \\
(0.0559)\end{array}$ \\
\hline Obs. & 110,691 & 110,543 & 110,543 & 110,543 & 399,259 & 399,259 & 399,259 & 399,259 \\
\hline$R^{2}$ & 0.004 & 0.016 & 0.023 & 0.023 & 0.042 & 0.044 & 0.046 & 0.046 \\
\hline Variáveis de controle & & SIM & SIM & SIM & & SIM & SIM & SIM \\
\hline Carac. municipais & & & SIM & SIM & & & SIM & SIM \\
\hline Erros clusterizados & & & & SIM & & & & SIM \\
\hline
\end{tabular}

Notas: A significancia estatistica dos resultados e representada por: ${ }^{* * *}$ Estatisticamente significante ao nivel de 1\%,** Estatisticamente significante ao nivel de 5\%, * Estatisticamente significante ao nivel de $10 \%$ 
Tabela A5 - Impacto da Lei de Cotas sobre a escolha de escola - Segundo grupo de controle $\left(1^{a}\right.$ serie do EM)

\begin{tabular}{|c|c|c|c|c|c|c|c|c|}
\hline & \multicolumn{4}{|c|}{ Minas Gerais } & \multicolumn{4}{|c|}{ São Paulo } \\
\hline & (1) & $(2)$ & (3) & $(4)$ & (1) & (2) & (3) & (4) \\
\hline \multicolumn{9}{|c|}{ Painel A: Duas coortes (2011 e 2012) } \\
\hline ano & $\begin{array}{c}0.0160^{* * *} \\
(0.00198)\end{array}$ & $\begin{array}{c}0.0164^{* * * *} \\
(0.00210)\end{array}$ & $\begin{array}{c}0.0200^{* * *} \\
(0.00219)\end{array}$ & $\begin{array}{c}0.0200^{* * *} \\
(0.00418)\end{array}$ & $\begin{array}{c}0.00604^{* * *} \\
(0.00109)\end{array}$ & $\begin{array}{c}0.00693^{* * *} \\
(0.00110)\end{array}$ & $\begin{array}{c}0.00728^{* * *} \\
(0.00231)\end{array}$ & $\begin{array}{c}0.00728^{* * *} \\
(0.00231)\end{array}$ \\
\hline trat & $\begin{array}{c}0.0601^{* * *} \\
(0.00230)\end{array}$ & $\begin{array}{c}0.0590 * * * \\
(0.00229)\end{array}$ & $\begin{array}{c}0.0593^{* * *} \\
(0.00228)\end{array}$ & $\begin{array}{c}0.0593^{* * *} \\
(0.00466)\end{array}$ & $\begin{array}{l}0.108^{* * *} \\
(0.00138)\end{array}$ & $\begin{array}{l}0.107^{\text {*** }} \\
(0.00138)\end{array}$ & $\begin{array}{l}0.107^{* * *} \\
(0.00339)\end{array}$ & $\begin{array}{l}0.107^{* * *} \\
(0.00339)\end{array}$ \\
\hline Lei de Cotas & $\begin{array}{c}0.0109^{* * *} \\
(0.00343)\end{array}$ & $\begin{array}{c}0.0113^{* * *} \\
(0.00342)\end{array}$ & $\begin{array}{c}0.0113 * * * \\
(0.00340)\end{array}$ & $\begin{array}{c}0.0113 \\
(0.00705)\end{array}$ & $\begin{array}{c}0.00728^{* * *} \\
(0.00198)\end{array}$ & $\begin{array}{c}0.00742^{* * *} \\
(0.00198)\end{array}$ & $\begin{array}{c}0.00718 \\
(0.00469)\end{array}$ & $\begin{array}{c}0.00718 \\
(0.00469)\end{array}$ \\
\hline IDEB & & $\begin{array}{l}-0.00176 \\
(0.00251)\end{array}$ & $\begin{array}{c}-0.0154^{* * *} \\
(0.00342)\end{array}$ & $\begin{array}{c}-0.0154^{* *} \\
(0.00756)\end{array}$ & & $\begin{array}{c}-0.0134^{* * *} \\
(0.00161)\end{array}$ & $\begin{array}{c}-0.0139^{* *} \\
(0.00633)\end{array}$ & $\begin{array}{c}-0.0139^{* *} \\
(0.00633)\end{array}$ \\
\hline OR & & $\begin{array}{c}-0.0479^{* * *} \\
(0.00197)\end{array}$ & $\begin{array}{c}-0.0217^{* * *} \\
(0.00232)\end{array}$ & $\begin{array}{c}-0.0217^{* * *} \\
(0.00446)\end{array}$ & & $\begin{array}{c}-0.0331^{* * *} \\
(0.00138)\end{array}$ & $\begin{array}{c}-0.0157^{* * *} \\
(0.00427)\end{array}$ & $\begin{array}{c}-0.0157^{* * *} \\
(0.00427)\end{array}$ \\
\hline Desigualdade de Renda & & & $\begin{array}{c}-0.345^{* * *} \\
(0.0473)\end{array}$ & $\begin{array}{c}-0.345^{* * *} \\
(0.106)\end{array}$ & & & $\begin{array}{c}-0.448^{* * * *} \\
(0.0661)\end{array}$ & $\begin{array}{c}-0.448 * * * \\
(0.0661)\end{array}$ \\
\hline Pobreza & & & $\begin{array}{c}0.00305^{* * *} \\
(0.000496)\end{array}$ & $\begin{array}{c}0.00305^{* * *} \\
(0.00115)\end{array}$ & & & $\begin{array}{c}0.00641^{* * * *} \\
(0.00140)\end{array}$ & $\begin{array}{c}0.00641^{* * *} \\
(0.00140)\end{array}$ \\
\hline Renda per capita & & & $\begin{array}{l}-4.31 \mathrm{e}-06 \\
(1.30 \mathrm{e}-05)\end{array}$ & $\begin{array}{l}-4.31 \mathrm{e}-06 \\
(3.17 \mathrm{e}-05)\end{array}$ & & & $\begin{array}{c}1.06 \mathrm{e}-05 \\
(1.40 \mathrm{e}-05)\end{array}$ & $\begin{array}{c}1.06 \mathrm{e}-05 \\
(1.40 \mathrm{e}-05)\end{array}$ \\
\hline População & & & $\begin{array}{c}8.28 \mathrm{e}-11^{* * *} \\
0\end{array}$ & $\begin{array}{c}8.28 \mathrm{e}-11 \\
(5.12 \mathrm{e}-11)\end{array}$ & & & $\begin{array}{c}0^{* * * *} \\
0\end{array}$ & $\begin{array}{c}0^{* * * *} \\
0\end{array}$ \\
\hline IDHM Educação & & & $\begin{array}{c}-0.167^{* * *} \\
(0.0270)\end{array}$ & $\begin{array}{c}-0.167^{* *} \\
(0.0722)\end{array}$ & & & $\begin{array}{l}0.142^{* *} \\
(0.0619)\end{array}$ & $\begin{array}{l}0.142^{* *} \\
(0.0619)\end{array}$ \\
\hline Constante & $\begin{array}{c}0.0490^{* * *} \\
(0.00131)\end{array}$ & $\begin{array}{c}0.105^{* * *} \\
(0.0108)\end{array}$ & $\begin{array}{c}0.412^{* * *} \\
(0.0273)\end{array}$ & $\begin{array}{c}0.412^{* * *} \\
(0.0661)\end{array}$ & $\begin{array}{c}0.0514^{* * *} \\
(0.000758)\end{array}$ & $\begin{array}{l}0.143^{* * *} \\
(0.00734)\end{array}$ & $\begin{array}{c}0.216^{* * *} \\
(0.0564)\end{array}$ & $\begin{array}{c}0.216^{* * *} \\
(0.0564)\end{array}$ \\
\hline Obs. & 109,595 & 109,472 & 109,472 & 109,472 & 375,343 & 375,343 & 375,343 & 375,343 \\
\hline$R^{2}$ & 0.015 & 0.021 & 0.029 & 0.029 & 0.031 & 0.032 & 0.034 & 0.034 \\
\hline Painel B: Seis coortes & $2009-2014)$ & & & & & & & \\
\hline ano & $\begin{array}{c}0.0156^{* * *} \\
(0.00116)\end{array}$ & $\begin{array}{c}0.0166^{* * * *} \\
(0.00131)\end{array}$ & $\begin{array}{c}0.0219^{* * *} \\
(0.00141)\end{array}$ & $\begin{array}{c}0.0219^{* * *} \\
(0.00281)\end{array}$ & $\begin{array}{c}0.00855^{* * *} \\
(0.000638)\end{array}$ & $\begin{array}{l}0.0101^{* * *} \\
(0.000691)\end{array}$ & $\begin{array}{c}0.0113^{* * *} \\
(0.000699)\end{array}$ & $\begin{array}{c}0.0113^{* * *} \\
(0.00147)\end{array}$ \\
\hline trat & $\begin{array}{c}0.0630^{* * *} \\
(0.00136)\end{array}$ & $\begin{array}{c}0.0624^{* * *} \\
(0.00135)\end{array}$ & $\begin{array}{c}0.0625 * * * \\
(0.00135)\end{array}$ & $\begin{array}{c}0.0625^{* * *} \\
(0.00278)\end{array}$ & $\begin{array}{c}0.117^{* * *} \\
(0.000828)\end{array}$ & $\begin{array}{c}0.116^{* * *} \\
(0.000827)\end{array}$ & $\begin{array}{c}0.116^{* * *} \\
(0.000825)\end{array}$ & $\begin{array}{l}0.116^{* * *} \\
(0.00224)\end{array}$ \\
\hline Lei de Cotas & $\begin{array}{c}0.0177^{* * *} \\
(0.00202)\end{array}$ & $\begin{array}{c}0.0171^{* * *} \\
(0.00202)\end{array}$ & $\begin{array}{c}0.0170^{* * *} \\
(0.00201)\end{array}$ & $\begin{array}{c}0.0170^{* * *} \\
(0.00421)\end{array}$ & $\begin{array}{c}-0.00880^{* * *} \\
(0.00116)\end{array}$ & $\begin{array}{c}-0.00991^{* * *} \\
(0.00119)\end{array}$ & $\begin{array}{c}-0.0101^{* * *} \\
(0.00119)\end{array}$ & $\begin{array}{c}-0.0101^{* * *} \\
(0.00291)\end{array}$ \\
\hline IDEB & & $\begin{array}{c}-0.00875^{* * *} \\
(0.00140)\end{array}$ & $\begin{array}{c}-0.0175^{* * *} \\
(0.00177)\end{array}$ & $\begin{array}{c}-0.0175 * * * \\
(0.00410)\end{array}$ & & $\begin{array}{c}-0.0151^{* * *} \\
(0.000938)\end{array}$ & $\begin{array}{c}-0.0181^{* * *} \\
(0.00126)\end{array}$ & $\begin{array}{c}-0.0181^{* * * *} \\
(0.00373)\end{array}$ \\
\hline OR & & $\begin{array}{c}-0.0451^{* * *} \\
(0.00117)\end{array}$ & $\begin{array}{c}-0.0239^{* * *} \\
(0.00134)\end{array}$ & $\begin{array}{c}-0.0239^{* * *} \\
(0.00281)\end{array}$ & & $\begin{array}{l}-0.0305^{* * *} \\
(0.000784)\end{array}$ & $\begin{array}{c}-0.0119^{* * *} \\
(0.000905)\end{array}$ & $\begin{array}{c}-0.0119^{\text {*** }} \\
(0.00254)\end{array}$ \\
\hline Desigualdade de Renda & & & $\begin{array}{c}-0.402^{* * *} \\
(0.0280)\end{array}$ & $\begin{array}{c}-0.402^{* * *} \\
(0.0638)\end{array}$ & & & $\begin{array}{c}-0.479^{* * *} \\
(0.0150)\end{array}$ & $\begin{array}{c}-0.479 * * * \\
(0.0398)\end{array}$ \\
\hline Pobreza & & & $\begin{array}{c}0.00320 * * * \\
(0.000290)\end{array}$ & $\begin{array}{c}0.00320 * * * \\
(0.000698)\end{array}$ & & & $\begin{array}{c}0.00589^{* * * *} \\
(0.000317)\end{array}$ & $\begin{array}{c}0.00589^{* * *} \\
(0.000837)\end{array}$ \\
\hline Renda per capita & & & $\begin{array}{l}1.72 \mathrm{e}-05^{* *} \\
(7.52 \mathrm{e}-06)\end{array}$ & $\begin{array}{c}1.72 \mathrm{e}-05 \\
(1.87 \mathrm{e}-05)\end{array}$ & & & $\begin{array}{c}8.31 \mathrm{e}-06^{* * *} \\
(3.07 \mathrm{e}-06)\end{array}$ & $\begin{array}{c}8.31 \mathrm{e}-06 \\
(8.26 \mathrm{e}-06)\end{array}$ \\
\hline População & & & $\begin{array}{c}6.55 \mathrm{e}-11^{* * *} \\
0\end{array}$ & $\begin{array}{c}6.55 \mathrm{e}-11^{* *} \\
0\end{array}$ & & & $\begin{array}{c}0^{* * * *} \\
0\end{array}$ & $\begin{array}{c}0^{* * * *} \\
0\end{array}$ \\
\hline IDHM Educação & & & $\begin{array}{c}-0.160^{* * *} \\
(0.0156)\end{array}$ & $\begin{array}{c}-0.160^{* * *} * \\
(0.0412)\end{array}$ & & & $\begin{array}{c}0.0979^{* * *} \\
(0.0140)\end{array}$ & $\begin{array}{c}0.0979^{* * *} \\
(0.0374)\end{array}$ \\
\hline Constante & $\begin{array}{l}0.0492^{* * *} \\
(0.000771)\end{array}$ & $\begin{array}{c}0.130^{* * *} \\
(0.00593)\end{array}$ & $\begin{array}{c}0.426^{* * *} \\
(0.0154)\end{array}$ & $\begin{array}{c}0.426^{* * * *} \\
(0.0385)\end{array}$ & $\begin{array}{l}0.0508^{* * *} \\
(0.000446)\end{array}$ & $\begin{array}{l}0.147^{* * *} \\
(0.00420)\end{array}$ & $\begin{array}{c}0.282^{* * * *} \\
(0.0123)\end{array}$ & $\begin{array}{c}0.282^{* * * *} \\
(0.0334)\end{array}$ \\
\hline Obs. & 320,929 & 320,622 & 320,622 & 320,622 & $1,111,771$ & $1,045,723$ & $1,045,723$ & $1,045,723$ \\
\hline$R^{2}$ & 0.017 & 0.022 & 0.029 & 0.029 & 0.031 & 0.032 & 0.035 & 0.035 \\
\hline Variáveis de controle & & SIM & SIM & SIM & & SIM & SIM & SIM \\
\hline Carac. municipais & & & SIM & SIM & & & SIM & SIM \\
\hline Erros clusterizados & & & & SIM & & & & SIM \\
\hline
\end{tabular}

Notas: A significancia estatistica dos resultados e representada por: *** Estatisticamente significante ao nivel de 1\%, ** Estatisticamente significante ao nivel de 5\%, * Estatisticamente significante ao nivel de $10 \%$ 